\title{
A Comparative Study on the Shear Behaviour of an Interlayer Material Based on Laboratory and In-situ Shear Tests
}

4

${ }^{1} \mathrm{Ph}$. D candidate, State Key Laboratory of Geomechanics and Geotechnical Engineering, Institute of Rock and Soil Mechanics, Chinese Academy of Sciences, Wuhan, China 430071, EMail: ben_johnson@163.com

${ }^{2}$ Professor, State Key Laboratory of Geomechanics and Geotechnical Engineering, Institute of Rock and Soil Mechanics, Chinese Academy of Sciences, Wuhan, China 430071, E-Mail: xtfeng@whrsm.ac.cn

$*^{3}$ Corresponding author, Professor, UMR NAVIER/CERMES, Ecole des Ponts ParisTech, 6 et 8 av. Blaise Pascal, 77455 MARNE-LA-VALLEE CEDEX 2, France, E-mail: yujun.cui@enpc.fr

${ }^{4}$ Engineer, East China Investigation and Design Institute, China Hydropower Engineering Consulting Group Co., Hangzhou, China 310014, E-mail: jiang_yl@ecidi.com

${ }^{5}$ Engineer, East China Investigation and Design Institute, China Hydropower Engineering Consulting Group Co., Hangzhou, China 310014, E-mail: huang_k@ecidi.com 


\section{Abstract}

28 In order to evaluate the overall stability of the underground powerhouse at the future Baihetan hydropower station in China, the shear strength of a weak intercalation soil in the host rock has been investigated by carrying out in-situ direct shear and laboratory shear tests. A comparative study was performed based on the two testing results. It has been observed that both tests show elastic perfect-plastic behaviour. A significant heterogeneity of the samples has been identified under both laboratory and field conditions. The samples disturbance seems to be a factor less important compared to the samples variability. The size effect has been evidenced by the greater friction angle obtained in the laboratory on small samples than that obtained in the field on larger samples. The clay fraction has been found to be an important factor; its increase reduces the friction angle and increases the cohesion. Without considering some particular data due to the soil heterogeneity, a negligible effect of initial degree of saturation has been identified. Comparison between the results from the field tests with that from the laboratory tests in terms of effects of the clay fraction and initial degree of saturation shows a good consistency, indicating a relatively secondary effect of samples size and samples variability.

42

Keywords: Baihetan site; interlayer staggered zone; laboratory shear test; in-situ shear test; shear behaviour; comparative study. 


\section{Introduction}

At future Baihetan hydropower station in China, there is a weak intercalation soil in the host rocks (tuff and basalt) that represents a potential threat to the overall stability of underground powerhouse due to its relatively poor mechanical properties. The location of the planed hydropower station is shown in Fig.1, on the downstream of Jinsha River. It is one of the largest multipurpose water conservancy projects in China. In the preliminary design by the East China Investigation and Design Institute (ECIDI), the hydropower station is made up of three parts, i.e. the underground powerhouse, the dam and the navigation facility. The underground powerhouse covers both sides of the river in the downstream direction, with the buried depths of $350 \mathrm{~m}$ on the left bank and $550 \mathrm{~m}$ on the right bank. It is composed of a main powerhouse cavern, a main transformation cavern and a tailrace surge tank, whose dimensions are $439 \times 32.2 / 29 \times 90 \mathrm{~m}$, $400 \times 20.5 \times 32 \mathrm{~m}$ and $311 \times 28.5 / 26.5 \times 88.42 \mathrm{~m}$, respectively. The horizontal distances from the powerhouse area to the toes of the mountain are respectively $515 \mathrm{~m}$ on the left bank and $530 \mathrm{~m}$ on the right bank. Preliminary calculation shows that these distances are sufficient to ensure the powerhouse stability under unloading induced by river erosion and cutting $(102 \mathrm{~m}$ on the left bank and $62 \mathrm{~m}$ depth on the right bank). Five slightly inclined interlayer staggered zones (No.1, No.2, No.3, No.4 and No.5) with thickness ranging from 50 to $300 \mathrm{~mm}$ (Fig.2, in testing tunnel No.62) are found in the powerhouse regions. Fig.3 shows the geological map of the underground powerhouse site at an elevation of $624 \mathrm{~m}$ above the see level where testing tunnel No.62 is located. From the figure, it can be seen that the No.4 and No.5 interlayer staggered zones cross the testing tunnel at this elevation. Due to their large scope at this site the No.1, No.4 and No.5 interlayer staggered zones outcropped in the upper part of the high walls or arch of the powerhouse.

Fig. 4 shows the grain size distribution curves of the interlayer material from the 5 zones. It can be observed that the interlayer material is generally coarse-grained soils with large $d_{50}$ values: $0.3 \mathrm{~mm}, 0.9 \mathrm{~mm}, 2.5 \mathrm{~mm}, 0.15 \mathrm{~mm}$ and $5 \mathrm{~mm}$ for zone No.1, No.2, No.3, No.4 and No.5, respectively. In the testing tunnels, the key role of water action in the grain size of interlayer material was observed: in the zones with small grain size, water flow through fractures can be seen whilst in the zones with large grain size no water flow can be identified. In other words, water flow enhances the formation of fine-grained soils: the more intense the water flow the clayeyer the interlayer material. This explains the great difference of the physical properties (water content $w$, unit mass $\rho$, specific gravity $G_{\mathrm{s}}$, void ratio $e$, degree of saturation $S_{\mathrm{r}}$, liquid limit $w_{\mathrm{L}}$, plastic limit $w_{\mathrm{P}}$, etc.) between different interlayer materials (see Table 1). The clay minerals determined by X-ray diffractometry are illite, montmorillonite, halloysite and kaolinite.

From a mechanical point of view, the shear strength of both interlayer soils and soils/rock interface is much lower than the host rocks, and as a result, when excavating shear failure could occur either in the soils or at the soil-rock interface. Thus the question of the stability of the underground powerhouse is arisen and the shear strength behaviour of the interlayer staggered zone is needed to be investigated.

The shear behaviour of interlayer staggered zone has been studied by number of researchers by developing testing methods, studying the shear strength and elaborating constitutive models. Xu (1980) considered the interlayer soil as a typical rheological material and observed from field creep tests that the creep process was composed of three stages: decelerated creep, steady creep 
and accelerated creep. Chen and $\mathrm{Li}$ (1980) observed that the relaxation of interlayer soils is an important mechanism. Li et al. (1983) carried out two laboratory tests on the interlayer soil, including simple shear creep test and shear stress relaxation test, to investigate its long-term shear strength behaviour. Dong et al. (1994) performed field shear tests at controlled displacement rate with monitoring of pore pressure and analysed the dissipation of pore pressure during consolidation and shearing. Recently, the shear behaviour of completely decomposed granite (CDG) soil, which is similar to the interlayer material, was studied using various test apparatus and methods. For instance, Chu and Yin $(2005,2006)$ adopted direct shear box tests to investigate the interface shear behaviour between the soil nails and CDG soil. Hossain and Yin (2010) studied the shear strength and dilative characteristics of CDG soil by performing a series of single-stage consolidated drained direct shear tests under different matric suctions and net normal stresses. They found that the shear strength of CDG soil increases with matric suction and net normal stress. The phenomenon, i.e., a greater dilation angle at higher suctions with lower net normal stresses and lower or zero dilation angles under higher net normal stresses with lower suctions, was observed.

As far as the creep and strength models for interlayer material are concerned, Ge (1979) and Ge et al. (1982) elaborated a creep model based on the field shear test results and applied it to analyse the rock displacement of the foundation pit at the site of Gezhouba dam in China. In order to describe the primary, steady and accelerated creep stages under constant shear stress and based on the laboratory shear tests on saturated interlayer samples, Xiao et al. (1986) proposed a complex creep model made up of elastic, plastic and viscous components connected in series/parallel. Regarding the shear strength, Oliveira et al. (2009) have presented a critical review on the existing models for infilled materials and modified the normalised peak shear stress model based on the shear tests on the idealised saw-tooth joints.

To study the shear strength behaviour of the interlayer material at Baihetan site, both in-situ shear and laboratory shear tests have been carried out. This paper aims at making a comparison of the results from the tests under two different conditions. This comparison is expected to be helpful for better understanding the shear behaviour of the interlayer material and adopting reasonable strength parameters in constitutive models.

\section{Materials and Methods}

\section{In-situ shear testing}

In-situ direct shear tests on interlayer material were carried out at the testing tunnel bottom part where interlayer staggered zone is found based on the Chinese Standard SL264-2001. According to this standard, in-situ sample size should be larger than $500 \mathrm{~mm} \times 500 \mathrm{~mm} \times h \mathrm{~mm}(h \geq 350$ $\mathrm{mm}$ ). For the test by multi-sample method (MSM), 5 in-situ rock blocks in size of about $500 \mathrm{~mm}$ $\times 500 \mathrm{~mm} \times 350 \mathrm{~mm}$ were carefully trimmed to prepare samples in the testing tunnel. Fig.5 depicts the sketch of sample for the in-situ test. For each sample, the lower part corresponds to the underlying rock, and was below the ground surface; the interlayer material is at the level of the ground surface and under the upper rock block. Weak or fractured rock blocks were encapsulated using concrete mould and maintained under field condition for more than 14 days until the strength of concrete mould achieved the testing requirement. Fig.6 shows the schematic layout of the in-situ direct shear test. Before testing, normal loading system and shear loading system were carefully installed in turn to ensure the resultant force to be at the centre of the 
interlayer material. In order to guarantee the space for normal deformation, a 10-mm gap between the prefixed plane and the bottom of backing plate was initially kept. When testing, a prescribed normal stress $\sigma_{\mathrm{n}}$ was first applied and the vertical displacement was monitored using displacement gauges. In order to avoid the extrusion of interlayer material especially at high initial degree of saturation, as discussed by Sun and Zhao (1980), a normal stress lower than 1.5 MPa was applied in 4 steps of 5-min duration. Equilibrium was considered as reached when the displacement rate is lower than $0.03 \mathrm{~mm} / 10 \mathrm{~min}$. Shear stress $\tau$ was then applied under constant normal stress until the sample reached failure or the shear displacement $\left(u_{\mathrm{s}}\right)$ was larger than 15 $\mathrm{mm}$ along the prefixed plane. A total of $8-12$ shear loading steps of $10 \mathrm{~min}$ each were considered. This procedure was repeated when testing other samples at different values of $\sigma_{\mathrm{n}}$. The results allowed the determination of the strength parameters. As shown in Table 2, the degrees of saturation of the samples were high, from $73.0 \%$ to $99.5 \%$.

\section{Laboratory shear testing}

Two laboratory shear tests were performed, including the direct shear test using the shear system RMT150C (Fig.7) and the shear creep tests using the system JQ-200 (Fig.8). When conducting direct shear test on RMT150C, normal stress was applied through an adjustable vertical piston and shear was applied through a horizontal loading system that drives two horizontal dowels pushing the upper shear box. The dimensions of the samples for these tests were $150 \mathrm{~mm} \times 150$ $\mathrm{mm} \times 150 \mathrm{~mm}$, with the interlayer material in the middle and the concrete blocks at both the top and bottom (see in Fig.7 and Fig.8). In the sample, the block interlayer was taken from a block with a dimension of $180 \mathrm{~mm} \times 180 \mathrm{~mm} \times h \mathrm{~mm}$ ( $h$ was the thickness of interlayer material). Note that the interlayer blocks were dug from testing tunnel No.41 (near the left bank powerhouse region whose depth is $350 \mathrm{~m}$ ) and testing tunnel No.62 (in the right bank powerhouse region whose depth is $550 \mathrm{~m}$ ). Before preparing laboratory shear test samples, the block interlayer material was first cut carefully into a sub-block of $150 \mathrm{~mm} \times 150 \mathrm{~mm} \times t \mathrm{~mm}(t$ was the thickness of interlayer material, $t \leq h)$. After that, the sample was prepared using a metal mould without upper and lower covers, as follows: pouring the concrete with the quantity needed to reach the lower concrete height calculated previously according to the thickness of interlayer material; putting the sub-block on the lower concrete; pouring the upper concrete with the quantity needed to reach the upper concrete height calculated previously; disassembling the metal mould and conserving the sample in a vertical position under indoor condition. Note that the thickness $t$ was in general more than $30 \mathrm{~mm}$, enough to ensure the shear failure to occur in it. In order to analyze the effect of initial degree of saturation, laboratory direct shear tests were conducted at much lower degree of saturation (see Table 3 and Table 4, ranging from $17.9 \%$ to $48.7 \%$ ) than that in field (ranging from $73 \%$ to $99.5 \%$ ). However, Greater values of degree of saturation were considered in the laboratory when investigating its effect on the creep behaviour.

Two methods, i.e. MSM for direct shear testing and Single-sample method (SSM, see Zhang et al., 1994) for direct shear and shear creep testing, were adopted. For direct shear test by MSM, the procedure is similar to the in-situ direct tests described above. For direct shear test by SSM, normal stress and shear stress were step loaded alternatively. In the first step loading, normal stress was applied in 4 steps of 5-min duration each. When peak point or constant $\tau$ was observed on $\tau$ - $u_{\mathrm{s}}$ curve during a step loading, the next step $\sigma_{\mathrm{n}}$ and $\tau$ are applied. By varying $\sigma_{\mathrm{n}}$ and $\tau$ more than 4 times before the sample failure, the $\tau-\sigma_{\mathrm{n}}$ plot can be drawn and then shear strength parameters can be determined. For shear creep test by SSM, the procedure follows the Chinese 
Industry Standard SL264-2001: shear stress was applied in more than 5 steps on a sample under a prescribed normal stress, with each loading step kept for longer than 5 days. Note that the sample area correction was applied for direct shear tests when calculating the stress values, and as a result, the normal stress before the first shear loading by MSM corresponds to the initial normal stress and the $\tau$ - $u_{\mathrm{s}}$ curves seem to increase even after failure.

\section{Experimental results}

In-situ tests

Fig.9a shows the $\tau-u_{\mathrm{s}}$ curve from the test in zone 1 on the interlayer material at a degree of saturation of $76.6 \%$. Note that due to a technique problem, the vertical deformation was not available. It can be observed from the figure that i) only the test under a normal stress of 1.05 MPa depicts a peak shear stress, other tests showing a plateau of stabilisation; ii) only the increase of the maximum shear stress when increasing the normal stress from $0.34 \mathrm{MPa}$ to 0.46 $\mathrm{MPa}$ is significant, the values for other tests are close. Normally, for a given soil with increasing normal stress, the shear stress peak is less pronounced and the increase of maximum shear stress is proportional to the normal stress increase. The observations made on this test are to be attributed to the variability of the five test samples. Fig.9b depicts the results from the tests in zone 2 at an initial degree of saturation of $73.0 \%$. Only the test under $0.98 \mathrm{MPa}$ normal stress shows an apparent peak, other tests giving a plateau of stabilisation. The increase of maximum shear stress with increasing normal stress is more regular than the tests in zone 1, indicating a less pronounced variability of the tested samples. Fig.9c depicts the results from the tests in zone 3 at an initial degree of saturation of $96.6 \%$. No peaks are observed and all tests show a plateau of stabilisation. The increase of shear stress with increasing normal stress is also relatively regular, indicating that the samples tested are relatively similar. The test under 1.26 MPa normal stress shows a singular shape, with a sudden decrease of slope at about 0.40 MPa shear stress followed by an increase from 0.45 MPa shear stress. This phenomenon is suspected to be 'pores collapse' or 'grains crushing'. Further study is needed to investigate this fundamental phenomenon. Fig.9d depicts the results from the tests in zone 4 at an initial degree of saturation of $93.5 \%$. Only the test under 1.02 MPa normal stress shows a singular behaviour with a shear stress continuously increasing, even exceeding the maximum value under a higher normal stress (1.26 MPa). Visual Examination of the tested sample confirms this observation; indeed, this sample shows an irregular shear surface with two parts of a difference of $30 \mathrm{~mm}$ in height (see Fig.10). Fig.9e depicts the results from the tests in zone 5 at an initial degree of saturation of $76.6 \%$. Normal behaviour can be observed: the shear stress increases regularly with increasing normal stress, showing a low variability between the tested samples.

The cohesion $c$ and friction angle $\varphi$ were determined based on the obtained $\tau$ - $u_{\mathrm{s}}$ curves, and are presented in Table 2. The results show a quite large scatter: the values of $\mathrm{c}$ range from 0.02 to $0.42 \mathrm{MPa}$ and the values of $\varphi$ ranges from $14^{\circ}$ to $38^{\circ}$. This large scatter can be attributed to the effects of degree of saturation (ranging from $73.0 \%$ to $99.5 \%$ ) and the clay fraction (ranging from 0 to $13.0 \%$ ); it can be also attributed to the heterogeneity of the samples as observed above.

\section{Laboratory tests}

Fig. 11 shows the results obtained from laboratory shear tests by MSM on the interlayer material from testing tunnel No.62 with the initial degree of saturation between $17.9 \%$ and $48.7 \%$, under different normal stresses: 2.0 MPa, 3.0 MPa, 4.0 MPa and 5.0 MPa. Note that a step-loading 
procedure was applied in these tests; this explains the observed shapes of the curves. The $\tau-u_{\mathrm{s}}$ curves show identical behaviour when the shear stress is lower than $1.5 \mathrm{MPa}$, indicating, to a certain extent, a similar elastic behaviour. Beyond 1.5 MPa shear stress, the shear stress is higher with a higher normal stress. The $u_{n}$ - $u_{s}$ curves $\left(u_{n}\right.$ is the vertical displacement) do not show any shear dilatancy: the volume change is compressive for all the tests conducted. Similar behaviour is observed for $u_{\mathrm{n}}<0.5 \mathrm{~mm}$. Interestingly, this range corresponds to the range of $\tau<1.5 \mathrm{MPa}$ identified above on the $\tau$ - $u_{\mathrm{s}}$ curves. Examination of the $u_{\mathrm{n}}-u_{\mathrm{s}}$ curves corresponding to 2.0 and 3.0 $\mathrm{MPa}$ normal stress shows that the material is more compressive under higher normal stress; this is normal behaviour generally observed on other soils. A problem can be identified on the curves of $4.0 \mathrm{MPa}$ and 5.0 $\mathrm{MPa}$ normal stress: the curve of $\sigma_{\mathrm{n}}=4.0 \mathrm{MPa}$ shows much larger compression than that of $\sigma_{\mathrm{n}}=5.0 \mathrm{MPa}$. This can be attributed to the heterogeneity of the soil samples. Based on the $\tau-u_{\mathrm{s}}$ curves obtained, the values of $\sigma_{\mathrm{n}}$ and $\tau_{\mathrm{p}}$ at failure are determined and presented in Table 3. Fig.12 depicts the values of $\sigma_{\mathrm{n}}$ and $\tau_{\mathrm{p}}$ at failure from all the tests by MSM. It can be observed that it is difficult to obtain reasonable shear strength parameters due to the significant scatter of data.

Fig. 13 shows a typical result from the shear test by SSM on the interlayer material taken from testing tunnel No. 62 at an initial degree of saturation of $33.1 \%$. A total of 7 loading steps were applied. It can be observed from the $\tau$ - $u_{\mathrm{s}}$ curve that stabilisation was reached for each loading step. Examination of the $u_{\mathrm{s}}-u_{\mathrm{n}}$ curve shows that for most loading step the vertical displacement shows a quasi-immediate drop followed by a variation with a smaller slope. The shear strength parameters determined from the test results are presented in Table 4.

Fig. 13 depicts the creep behaviour in the $u_{\mathrm{s}}-t$ plane ( $t$ is the time) under a normal stress $\sigma_{\mathrm{n}}=$ $0.49 \mathrm{MPa}$ and at various shear stresses: $0.09 \mathrm{MPa}, 0.18 \mathrm{MPa}, 0.27 \mathrm{MPa}, 0.37 \mathrm{MPa}, 0.46 \mathrm{MPa}$, $0.55 \mathrm{MPa}, 0.64 \mathrm{MPa}$ and $0.74 \mathrm{MPa}$. It can be observed that the creep is not significant: under different shear stresses, the $u_{\mathrm{s}}-t$ curves show that most deformation occurs within a short time and the creep deformation is negligible. This differs from the previous studies in which interlayer material was considered as a rheological material (Xu 1980; Li and Kang 1983; Xiao 1987). From a practical point of view, this observation is of importance because relatively simple elastoplastic constitutive models can be used to describe the behaviour of interlayer material and there is no need to pay special attention to its creep behaviour. Moreover, the results from the creep tests can be used to determine the strength parameters.

It is to be noted that in the direct shear test, it is an important issue as to keep uniform vertical pressure on soil sample during shearing. Bathurst et al. (2008) carried out direct shear tests with three different loading methods for vertical stress, using: (1) a flexible airbag, (2) a fixed vertical piston, and (3) an adjustable vertical piston. They found that 1) the non uniform vertical stress distribution occurs when the soil shows shear dilatancy, almost uniform vertical stress being observed in all cases. and (2) the best method for keeping uniform vertical stress is the flexible airbag method. In this study, the method of adjustable piston method was employed, and in addition no dilatancy was observed during shearing (see Fig.11 and Fig.13). Thus, it is supposed that this phenomenon of non uniform vertical stress distribution was not significant in the present work.

\section{Comparative analysis based on in-situ and laboratory measurements}


Both in-situ and laboratory shear tests were carried out on the interlayer material. This allows a comparison between the results obtained under the two test conditions. This comparison can be done in terms of the effects of soil heterogeneity, sampling disturbance, sample size, clay fraction and initial degree of saturation. Because the vertical displacement was not obtained from the in-situ tests for technical problems, the study was limited to the comparison of the strength parameters: $c$ and $\varphi$. In addition, due to the difficulty of determining the strength parameters based on the results from the laboratory shear tests by MSM (see Fig.12), a special procedure of data treatment was then applied, as follows:

1) to attribute a relatively large value of $0.2 \mathrm{MPa}$ to $c$ based on the values from both laboratory direct shear tests by SSM and in-situ shear tests,

2) to back calculate $\varphi$ value based on the data according to the Mohr-Coulomb criterion (Eq. 1):

$$
\tau=c+\sigma_{\mathrm{n}} \tan \varphi
$$

The calculated values are presented in Table.3. It can be observed that relatively large values of friction angle were obtained, between $20.5^{\circ}$ and $38.7^{\circ}$. Note that the $\varphi$ values obtained from this special procedure of data treatment were not used to analyze the effects of clay fraction and initial degree of saturation.

\section{Effects of soil heterogeneity and sampling disturbance}

Soil heterogeneity is a common problem when dealing with intact natural materials. For the insitu tests, the heterogeneity caused significant data scatter and rendered the determination of strength parameters difficult (zone 1, see Fig. 9a). Some samples from the same zone showed different specific phenomenon as the suspected pores collapse or grains crushing (zone 3, see Fig. 9c). The difference between the samples from different sampling zone is quite large: the maximum shear stress value is about $0.50 \mathrm{MPa}$ for zone $1\left(\sigma_{\mathrm{n}}=1.05 \mathrm{MPa}\right), 1.70 \mathrm{MPa}$ for zone 2 $\left(\sigma_{\mathrm{n}}=1.26 \mathrm{MPa}\right), 0.75 \mathrm{MPa}$ for zone $3\left(\sigma_{\mathrm{n}}=1.26 \mathrm{MPa}\right), 0.36 \mathrm{MPa}$ for zone $4\left(\sigma_{\mathrm{n}}=1.26 \mathrm{MPa}\right)$, and $0.90 \mathrm{MPa}$ for zone $5\left(\sigma_{\mathrm{n}}=1.41 \mathrm{MPa}\right)$. As far as the laboratory tests are concerned, the results from MSM tests have depicted such a significant variability that the determination of shear parameters using the common results was not possible. The SSM method was then applied for this purpose. The results obtained have shown that this method is efficient and probably the only method allowing the direct determination of the shear strength parameters of the interlayer material.

Because both in-situ tests and laboratory tests involve the problem of sample disturbance, the samples do not reflect the real soil behaviour totally. Moreover, it is believed that this sample disturbance is more significant for the laboratory testing samples because (1)) the soil blocks are taken by removing the material in all directions, one direction more that the sample for in-situ testing; (2) there were transportation and conservation for the laboratory samples; (3) extra trimming was applied when preparing the laboratory samples. In spite of the unavoidable sample disturbance, as significant variability was observed when testing the interlayer material under both field and laboratory conditions, it seems that the problem related to the sample disturbance is not an important factor compared to the samples variability due to the material heterogeneity.

\section{Effects of sample size}

The shear plane for the laboratory samples is $150 \times 150 \mathrm{~mm}$ while the rock particles can reach a diameter of $100 \mathrm{~mm}$ (see Fig 4). The dimension and the proportion of these large rock particles 
in the soil matrix can play an important role in the shear strength determined, as reported by several authors (Holtz and Gibbs 1956; Dobbiah et al. 1969; Iannacchione and Vallejo 2000; Vallejo and Mawby 2000; Cerato and Lutenegger 2006; Fakhimi and Hosseinpour 2008). Holtz et al. (1956) showed that there is a critical fraction of coarse rock particles (35\%) that affect the shear behaviour of soil-rock mixture. Dobbiah et al. (1969) confirmed this observation but found a value of $50 \%$ for the critical fraction; this indicates that this value is dependent on the nature of the soil matrix and the coarse particles. If the fraction of rock particles is beyond this value, the shear strength is dominated by the particle-to-particle contacts. According to the China National Standards GB/T 50145-2007, the particle diameter of $0.075 \mathrm{~mm}$ is the border between finegrained particles and coarse particles. Following this definition, one can identify the coarse rock particles of the interlayer material based on the grain size distribution curves shown in Fig.4: $71 \%$ for zone $1 ; 77 \%$ for zone $2 ; 82 \%$ for zone $3 ; 59 \%$ for zone $4 ; 87 \%$ for zone 5 . Thus, all values are beyond the critical fraction. As a result, the behaviour must be dominated by coarse particles. Note however that as a natural soil, the interlayer material is significantly different from the artificially prepared soil-rock mixtures in which rock particles are uniformly distributed in soil matrix. With a randomly distributed rock particles in the sample, the effect of sample size must be greater: the determined strength parameters, especially the friction angle are in general larger in the case of small samples. It is indeed the case when comparing the friction angle obtained in the laboratory by MSM and SSM with that obtained in the filed (see Table 3 and Table 4).

As the difference between the values of friction angle by MSM and SSM is concerned, as described above, a relatively large value of cohesion $(0.2 \mathrm{MPa})$ was taken when estimated the friction angle based on the data from the laboratory direct shear tests by MSM. Note that this is justified by the fact that most values of cohesion from both laboratory direct shear tests by SSM and in-situ shear tests are smaller than $0.15 \mathrm{MPa}$ (see Table 2 and Table 4). In spite of this, the values obtained are in general greater than that from the laboratory direct shear tests by SSM (see Table 4), indicating that the MSM gives rise to greater friction angle values than the SSM. The same observation was made by other researchers on soft rock (Liu 1988; Zhang 1994). It has been concluded that for the same sample, because of cumulative damage during step loadings in the test by SSM, the shear strength is slightly lower than that from the tests by MSM.

\section{Effect of clay fraction}

Fig. 15a depicts the variation of friction angle with the clay fraction, under both the laboratory and field conditions. The values of initial void ratio and degree of saturation of some 'points' are indicated. A large variation of clay fraction can be observed, from 0 to $13 \%$, indicating a large heterogeneity of the samples. As a whole, the friction angle is decreasing with the increase of clay fraction (without considering some particular points); this is logical because fined-grained soils have relatively smaller fraction angles that coarse soils. The values obtained from the laboratory tests are consistent with that obtained from the in-situ tests. This seems to show that the size effect discussed above is not so important compared with the clay fraction effect.

Fig. 15b shows the variation of cohesion with the clay fraction, under both laboratory and field conditions. Some singular points are identified and the corresponding values of initial void ratio and degree of saturation are indicated in the figure. Despite the significant scatter of the data, an increase trend with clay fraction increase can be identified (without accounting for the particular 
data). This is also logical when considering its role of glue in the interlayer material. The values obtained from the laboratory tests are in general consistent with that from the field tests, indicating again a relatively less important sample size effect.

\section{Effect of initial degree of saturation}

It is well known that the shear strength of unsaturated soils is suction or degree of saturation dependent: the shear strength increases with suction increase (see for instance Fredlund et al. 1978; Fredlund and Rahardjo 1993). Delage and Cui (2001) analysed the data in the literature and found that the cohesion always increases with suction increase, whatever the soil nature. However, the friction angle can decrease or increase with suction increase, depending on the soil nature and the soil density: for clayey soils, no decrease can occur (Escario and Saez 1986); on the contrary for sandy soils (Escario and Saez 1986) and compacted silty soil (Maâtouk et al. 1995), a decrease can take place when the density is low (collapsible structure), and a slight increase can take place when the density is high (Delage and Cui 2001).

For the studied interlayer material, as shown in Table 1, the clay fraction is small and the density is quite high. Thus logically no friction angle decrease and a slight cohesion increase should be observed with suction increase or degree of saturation decrease. Fig.16a and Fig.16b depict the variation of friction angle and cohesion with the initial degree of saturation, respectively. The values of initial void ratio and clay fraction of some particular 'points' are indicated in the figures. Despite the significant data scatter, a negligible effect of initial degree of saturation can be identified, if the particular data were excluded. A good consistency can be also observed when comparing the results from the field tests with that from the laboratory tests, indicating again the relatively low effect of samples size.

\section{Conclusions}

In order to analyse the stability of the underground powerhouse at the future Baihetan hydropower station in China, the shear strength of the involved interlayer material has been investigated by carrying out both in-situ and laboratory shear tests. A comparative study was done in order to assess the effects of different factors as the heterogeneity, the samples disturbance, the samples size, the clay fraction and the initial degree of saturation. The following conclusions can be drawn:

1) the significant heterogeneity of the samples caused significant data scatter and rendered the determination of strength parameters difficult; it seems that the samples disturbance is not an important factor compared to the samples variability;

2) the samples are characterised by a randomly distributed coarse rock particles; this explains the greater friction angle obtained in the laboratory than that obtained in the field;

3) the friction angle is an important factor affecting the shear strength: the friction angle seems to decrease and the cohesion tends to increase with the increase of clay fraction;

4) without considering some particular data, a negligible effect of initial degree of saturation has been identified;

5) a good consistency has been observed when comparing the results from the field tests with that from the laboratory tests in terms of variations of friction angle and cohesion with the clay fraction and the initial degree of saturation, evidencing that the effects of 
samples size and samples variability are less important when compared with the effect of clay fraction, or to a less extent the initial degree of saturation.

\section{Acknowledgement}

The work is supported by National Special Funds of China for Major State Basic Research Project under Grant No. 2010CB732006, and by Chinese Academy of Sciences and State Administration of Foreign Experts Affairs, P.R of China, for the CAS/SAFEA International Partnership Program for Creative Research Teams under Grant No. KZCX2-YW-T12. The authors are grateful to ECIDI for providing the field test data.

\section{NOTATIONS:}

c cohesion

e void ratio

$\mathrm{G}_{\mathrm{s}} \quad$ specific gravity

$\mathrm{h} \quad$ the thickness of interlayer staggered zone in field

$\mathrm{S}_{\mathrm{r}} \quad$ degree of saturation

$\mathrm{t} \quad$ the thickness of interlayer material obtained from testing tunnels

$\mathrm{u}_{\mathrm{s}} \quad$ horizontal displacement

$\mathrm{u}_{\mathrm{n}} \quad$ vertical displacement

w water content

$\mathrm{w}_{\mathrm{L}} \quad$ liquid limit

$\mathrm{w}_{\mathrm{P}} \quad$ plastic limit

$\rho \quad$ unit mass

$\sigma_{\mathrm{n}} \quad$ normal stress

$\tau \quad$ shear stress

$\tau_{\mathrm{p}} \quad$ peak shear stress

$\varphi \quad$ friction angle

\section{References}

[1] Bathurst, R. J., Althoff, S., and Linnenbaum, P., 2008, "Influence of test method on direct shear behavior of segmental retaining wall units," Geotech. Test. J., Vol. 31, No. 2, pp. 1-9.

[2] Cerato, A.B., and Lutenegger, A.J., 2006, "Specimen size and scale effects of direct shear box tests of sands," Geotech. Test. J., Vol. 29, No. 6, pp. 507-516.

[3] Chen, Z. J.(Tan Tjong Kie), and Li, K. R., 1981, "Relaxation and creep properties of thin interbedded clayey seams and their fundamental role in the stability of dams," Proceedings of the International Symposium on Weak Rock, Tokyo, Japan, pp. 369-374.

[4] Chu, L. M., and Yin, J. H., 2005, "Comparison of Interface Shear Strength of Soil Nails Measured by both Direct Shear Box Tests and Pull-out Tests," J. Geotech. Geoenviron. Eng., Vol.131, No.9, pp.1097-1107.

[5] Chu, L. M., and Yin, J. H., 2006, "Study on Soil-Cement Grout Interface Shear Strength of Soil Nailing by Direct Shear Box Testing Method," Geomech. Geoeng.: An Int. J., Vol. 1, No.4, pp. 259-273.

[6] Delage, P., and Cui, Y. J., 2001, "Comportement mécanique des sols non saturés," Technique de l'Ingénieur, C302. 
[7] Dobbiah, D., Bhat, H. S., and Somasekhar, P. V., 1969, "Shear characteristics of soilgravel mixtures," J. India Nat. Soc. Soil Mech. Found. Eng., No. 8, pp. 57-66.

[8] Dong, Z. D., and Yuan, C. W., 1994, "Researches For Controlled Displacement-Rate Shear Test In Situ in Rock Mass Soft Intercalation," Chin. J. Rock Mech. Eng., Vol.16, No. 6, pp. 21-29.

[9] East China Investigation and Design Institute, 2006, "Engineering geology report for dam site selection of Baihetan hydropower station at feasibility study stage," Hangzhou, in Chinese.

[10]East China Investigation and Design Institute, 2008, "Preliminary design scheme of underground powerhouse at Baihetan hydropower station," Hangzhou, in Chinese.

[11]Escario V., and Saez J. 1986, "The shear strength of partly saturated soils," Géotechnique 36 (3), pp.453-456.

[12]Fakhimi, A., and Hosseinpour, H., 2008, "The role of oversize particles on the shear strength and deformational behavior of rock pile material," ARMA08-204, The 42nd US Rock Mechanics Symposium and 2nd US-Canada Rock Mechanics Symposium, San Francisco, USA.

[13]Fredlund, D. G., and Rahardjo, H., 1993, "Soil Mechanics for Unsaturated Soils," John Wiley and Sons, Inc. New York, N.Y.

[14] Fredlund, D. G., Morgenstern, N. R., and Widger, R.A., 1978, "The Shear Strength of Unsaturated Soils," Can. Geotech. J., Vol. 15, No. 3, pp. 313-321.

[15] Ge, X. R. (Ke Hsu Jun), 1979, "Non-linear Analysis of the Mechanical Properties of Joint and Weak Intercalation in Rock," Proceedings of the 3rd International Conference on Numerical Methods in Geomechanics, Aachen, Germany, Vol. 2, pp. 26.

[16] Ge, X. R., Feng, D. X., and Yang, J. L., 1982, "The Elasto-Visco-Plastic Analysis for Rock Displacement of the Foundation Pit of a Water Hydropower Plant," Rock Mech. Rock Eng., Vol. 15, No. 3, pp. 145-161.

[17] Holtz, W. G., and Gibbs, H. J., 1956, "Triaxial shear tests on pervious gravelly soils," J. Soil Mech. Found. Div. ASCE, Vol. 82, No.1, pp. 1-22.

[18]Hossain, M. A., and Yin, J. H., 2010, "Shear strength and dilative characteristics of an unsaturated compacted completely decomposed granite soil," Can. Geotech. J., Vol.47, No.10, pp. 1112-1126.

[19] Iannacchione, A. T., and Vallejo, L. E., "Shear Strength Evaluation of Clay-Rock Mixtures," Slope Stability 2000, Proceedings of Sessions of Geo-Denver 2000 Denver, Colorado, August 5-8, Geotechnical Special Publication No. 101, Editors; Griffiths D. V., Fenton G. A. and Martin T. R., Reston, VA: American Society of Civil Engineers, pp. 209-223.

[20] Li, K. R., and Kang, W. F., 1983, "Creep Testing of Thin Interbedded Clayey Seams in Rock and Determination of Their Long-term Strength," Chin. J. Rock Soil Mech., Vol. 4, No. 1, pp. 39-46.

[21] Liu, X., 1990, "A Study of Single Specimen Test Method for Determination of Shear Strength of Softrock," Chin. J. Rock Mech. Eng., Vol.9, No. 1, pp. 63-67.

[22] Maâtouk A., Leroueil S., and La Rochelle P. 1995, "Yielding and critical state of a collapsible unsaturated silty soil," Géotechnique 45 (3), 465-477. 
[23] Oliveira, D. A. F., Indraratna, B., and Nemcika, J., 2009, "Critical review on shear strength models for soil-infilled joints," Geomech. Geoeng.: An Int. J., Vol. 4, No.3, pp. 237-244.

[24]Sun, G. Z., and Zhao, R. H., 1984, "Normal stress for the shear test on weak intercalation," Chin. J. Hydrogeol. Eng. Geol., No.4, pp: 32-34.

[25] The Ministry of Water Resources of China, 2001, "China Industry Standards SL2642001: Specifications for Rock Tests in Water Conservancy and Hydroelectric Engineering," China Water Hydropower Press, Beijing.

[26] The Ministry of Water Resources of China, 2007, "China National Standards GB/T 50145-2007: Standard for engineering classification of soil," China Planning Press, Beijing.

[27] The Standardization Administration of China, the Ministry of Construction of China, and the Ministry of Water Resources of China, 1999, "China National Standards GB/T50123-1999: Standard for soil test method," China Planning Press, Beijing.

[28] Vallejo, L. E., and Mawby, R., 2000, "Porosity influence on the shear strength of granular material-clay mixtures," Eng. Geol., Vol. 58, No. 2, pp. 125-136.

[29] Xiao, S. F., Wang, X. F., and Chen Z. F., et al., 1986, "The Creep Model of the Intercalated Clay Layers and the Change of their Microstructure during Creep," Proceedings 5th International Congress International Association of Engineering Geology, Buenos Aires, Argentina, Vol. 4, pp. 2185-2192.

[30] Xu, D. J., 1980, "The Rheological Behaviour of the Weak Rock Mass and the Method of Determining Long-Term Strength," Chin. J. Rock Soil Mech., Vol. 2, No. 1, pp. 3750.

[31] Zhang, J. D., Liu, P. T., and Huang, C. J., 1994, "Mechanism for Shear Failure of Weak Structural Plane and Fissured Rock," Chin. J. Geotech. Eng., Vol. 16, No. 6, pp. 21-29. 


\section{List of Tables}

Table 1 Physical properties of interlayer material (ECIDI 2006)

Table. 2 Initial parameters of the samples and strength parameters for the in-situ tests

Table. 3 Initial parameters of the samples and strength parameters for the laboratory tests by MSM

Table.4 Initial parameters of the samples and strength parameters for the laboratory tests by SSM

Fig.1. Location of Baihetan hydropower station.

\section{List of Figures}

Fig.2. Interlayer staggered zone in testing tunnel No.41.

Fig.3. Geological map at an elevation of $624 \mathrm{~m}$ where testing tunnel No.62 is located (1) $\mathrm{P}_{2} \beta_{2}{ }^{3}$ : Aphanitic basalt, amygdaloidal basalt, breccia lava; (2) $\mathrm{P}_{2} \beta_{3}{ }^{1}$ : Aphanitic basalt, breccia lava with oblique basalt and amygdaloidal basalt with oblique basalt; (3) $\mathrm{P}_{2} \beta_{3}{ }^{2-1}$ : Amygdaloidal basalt; (4) $\mathrm{P}_{2} \beta_{3}{ }^{2-2}$ : Columnar jointed basalt; (5) $\mathrm{P}_{2} \beta_{3}{ }^{2-3}$ : Breccia lava; (6) $\mathrm{P}_{2} \beta_{3}{ }^{3}$ : Columnar jointed basalt; (7) $\mathrm{P}_{2} \beta_{3}{ }^{4}$ : Amygdaloidal basalt, aphanitic basalt and breccia lava; (8) $\mathrm{P}_{2} \beta_{3}{ }^{5}$ : Oblique basalt, breccia lava; (9) $\mathrm{P}_{2} \beta_{4}{ }^{1}$ : Columnar jointed basalt, amygdaloidal basalt, breccia lava and microcrystalline basalt; (10) $\mathrm{P}_{2} \beta_{4}{ }^{2}$ : Amygdaloidal basalt, breccia lava; (11) $\mathrm{P}_{2} \beta_{5}{ }^{1}$ : Aphanitic basalt and amygdaloidal basalt; (12) $\mathrm{P}_{2} \beta_{6}{ }^{1}$ : Columnar jointed basalt and breccia lava; (13) $\mathrm{P}_{2} \beta_{6}{ }^{2}$ : Aphanitic basalt and breccia lava; (14) $\mathrm{Q}_{4}{ }^{\text {col+dl: }}$ : Quaternary unconsolidated deposits.Fig.4. Grain size distribution of interlayer material.

Fig. 4. Particle Grain size distribution of interlayer material.

Fig. 5. The sketch of sample for the in-situ direct shear test

Fig.6. Schematic layout of in-situ direct shear test.

Fig.7. Schematic diagram of RMT150C.

Fig.8. Schematic diagram of JQ-200.

Fig.9. Typical results of interlayer materials of in-situ direct shear tests where the size of sample is 500 $\mathrm{mm} \times 500 \mathrm{~mm} \times 350 \mathrm{~mm}$ : from the interlayer staggered zone No.1 at an initial degree of saturation $S_{r}=$ $76.6 \%$ (a), from the interlayer staggered zone No.2 at an initial $S_{r}=73.0 \%(b)$, from the interlayer staggered zone No.3 at an initial $S_{r}=96.6 \%$ (c), from the interlayer staggered zone No.4 at an initial $S_{r}$ $=93.5 \%(d)$, and from the interlayer staggered zone No.5 at an initial $S_{r}=76.6 \%(e)$.

Fig.10. The shear surfaces of samples for a set of in-situ shear tests in zone 4: (a) normal shear surface, (b) irregular shear surface. The unit of numbers is centimeter, the negative number means the region is below the prefix shear plane and the arrowhead points at the shear direction.

Fig.11. Typical results of interlayer materials from laboratory direct shear test by MSM (the size of sample is $150 \mathrm{~mm} \times 150 \mathrm{~mm} \times 150 \mathrm{~mm}$ ) on the interlayer material from testing tunnel No.62 with the initial degree of saturation between $17.9 \%$ and $48.7 \%$.

Fig.12. Shear stress versus normal stress of laboratory direct shear test on interlayer material by MSM

Fig.13. Typical results of interlayer materials from laboratory direct shear test by SSM (the size of sample is $150 \mathrm{~mm} \times 150 \mathrm{~mm} \times 150 \mathrm{~mm}$ ) on the interlayer material from testing tunnel No.62 at an initial degree of saturation $S_{r}=33.1 \%$.

Fig.14. Typical results of shear creep test on interlayer material from testing tunnel No.4lat an initial degree of saturation $S_{r}=24.2 \%$ under an initial normal stress $\sigma_{n}=0.49 \mathrm{MPa}$.

Fig.15. Strength parameters versus clay fraction; (a) friction angle, (b) cohesion.

Fig.16. Strength parameters versus initial degree of saturation; (a) friction angle, (b) cohesion. 
TABLE 1-Physical properties of interlayer material (ECIDI 2006)

\begin{tabular}{|c|c|c|c|c|c|c|c|c|c|}
\hline \multirow{2}{*}{ No } & \multirow{2}{*}{$\begin{array}{l}\text { Clay fraction } \\
(<2 \mu \mathrm{m} \%)\end{array}$} & \multirow{2}{*}{$w(\%)$} & \multicolumn{2}{|c|}{$\rho\left(\mathrm{Mg} / \mathrm{m}^{3}\right)$} & \multirow{2}{*}{$G_{\mathrm{s}}$} & \multirow{2}{*}{$e$} & \multirow{2}{*}{$S_{\mathrm{r}}(\%)$} & \multirow{2}{*}{$w_{\mathrm{L}}(\%)$} & \multirow{2}{*}{$w_{\mathrm{P}}(\%)$} \\
\hline & & & wet & dry & & & & & \\
\hline 1 & 10.1 & 13.6 & 2.19 & 1.93 & 2.95 & 0.529 & 76.1 & 24.7 & 13.9 \\
\hline 2 & 7.1 & 13.4 & 2.27 & 1.98 & 2.88 & 0.455 & 84.9 & 24.9 & 14.7 \\
\hline 3 & 4.8 & 13.0 & 2.13 & 1.86 & 2.78 & 0.494 & 73.0 & 27.8 & 16.5 \\
\hline 4 & 13.8 & 14.8 & 2.25 & 1.96 & 2.83 & 0.447 & 93.5 & 24.7 & 14.1 \\
\hline 5 & 6.3 & 8.0 & 2.35 & 2.17 & 2.81 & 0.292 & 76.6 & - & - \\
\hline
\end{tabular}

- Values not available. Clay corresponds to the particle whose diameter is smaller than $0.005 \mathrm{~mm}$ according to the China National Standards GB/T 50145-2007.

TABLE 2-Initial parameters of the samples and strength parameters for the in-situ tests

\begin{tabular}{ccccc}
\hline No. & Clay fraction $(<5 \mu \mathrm{m} \%)$ & $S_{\mathrm{r}}(\%)$ & $c(\mathrm{MPa})$ & $\varphi\left({ }^{\circ}\right)$ \\
\hline 1 & 13.0 & 99.5 & 0.02 & 14.0 \\
1 & 11.0 & 76.6 & 0.13 & 21.3 \\
2 & 8.5 & 96.6 & 0.07 & 21.3 \\
2 & 0 & 73.0 & 0.42 & 38.0 \\
3 & 10.5 & 79.6 & 0.11 & 18.8 \\
3 & 12.0 & 85.6 & 0.03 & 21.3 \\
4 & 12.5 & 93.5 & 0.06 & 14.0 \\
5 & 0 & 76.6 & 0.05 & 25.6 \\
\hline
\end{tabular}

TABLE 3-Initial parameters of the samples and strength parameters for the laboratory tests by MSM

\begin{tabular}{|c|c|c|c|c|c|c|}
\hline \multirow{2}{*}{ No. } & \multirow{2}{*}{$\begin{array}{c}\text { Clay fraction } \\
(<5 \mu \mathrm{m} \%)\end{array}$} & \multirow{2}{*}{$S_{\mathrm{r}}(\%)$} & \multicolumn{2}{|c|}{ Failure envelope } & \multirow{2}{*}{$c^{*}(\mathrm{MPa})$} & \multirow{2}{*}{$\varphi^{*}\left({ }^{\circ}\right)$} \\
\hline & & & $\sigma_{\mathrm{n}}(\mathrm{MPa})$ & $\tau_{\mathrm{p}}(\mathrm{MPa})$ & & \\
\hline 1 & 5.7 & 27.5 & 2.08 & 1.74 & 0.2 & 36.5 \\
\hline 1 & 9.7 & 24.2 & 2.10 & 1.86 & 0.2 & 38.3 \\
\hline 4 & 10.0 & 38.6 & 2.33 & 2.07 & 0.2 & 38.7 \\
\hline 4 & 5.2 & 17.9 & 3.17 & 2.09 & 0.2 & 30.8 \\
\hline 4 & 9.5 & 41.8 & 4.10 & 1.73 & 0.2 & 20.5 \\
\hline 4 & 7.7 & 25.3 & 4.20 & 2.33 & 0.2 & 26.9 \\
\hline 4 & 7.0 & 32.1 & 5.26 & 3.28 & 0.2 & 30.4 \\
\hline 4 & 15.1 & 32.5 & 5.30 & 2.80 & 0.2 & 26.1 \\
\hline 4 & 13.5 & 48.7 & 5.41 & 4.09 & 0.2 & 35.7 \\
\hline
\end{tabular}

$c^{*}$ is assumed as $0.2 \mathrm{MPa}$ and $\varphi^{*}$ is back calculated using the Mohr-Coulomb strength criterion. 
TABLE 4-Initial parameters of the samples and strength parameters for the laboratory tests by SSM

\begin{tabular}{ccccc}
\hline No. & Clay fraction $(<5 \mu \mathrm{m} \%)$ & $S_{\mathrm{r}}(\%)$ & $c(\mathrm{MPa})$ & $\varphi\left({ }^{\circ}\right)$ \\
\hline 4 & 7.3 & 33.1 & 0.39 & 28.6 \\
1 & 5.2 & 33.3 & 0 & 20.8 \\
4 & 8.7 & 38.4 & 0 & 29.8 \\
4 & 7.0 & 32.2 & 0.051 & 27.1 \\
4 & 6.3 & 32.2 & 0.011 & 23.6 \\
4 & 10.4 & 29.6 & 0.079 & 23.4 \\
\hline
\end{tabular}

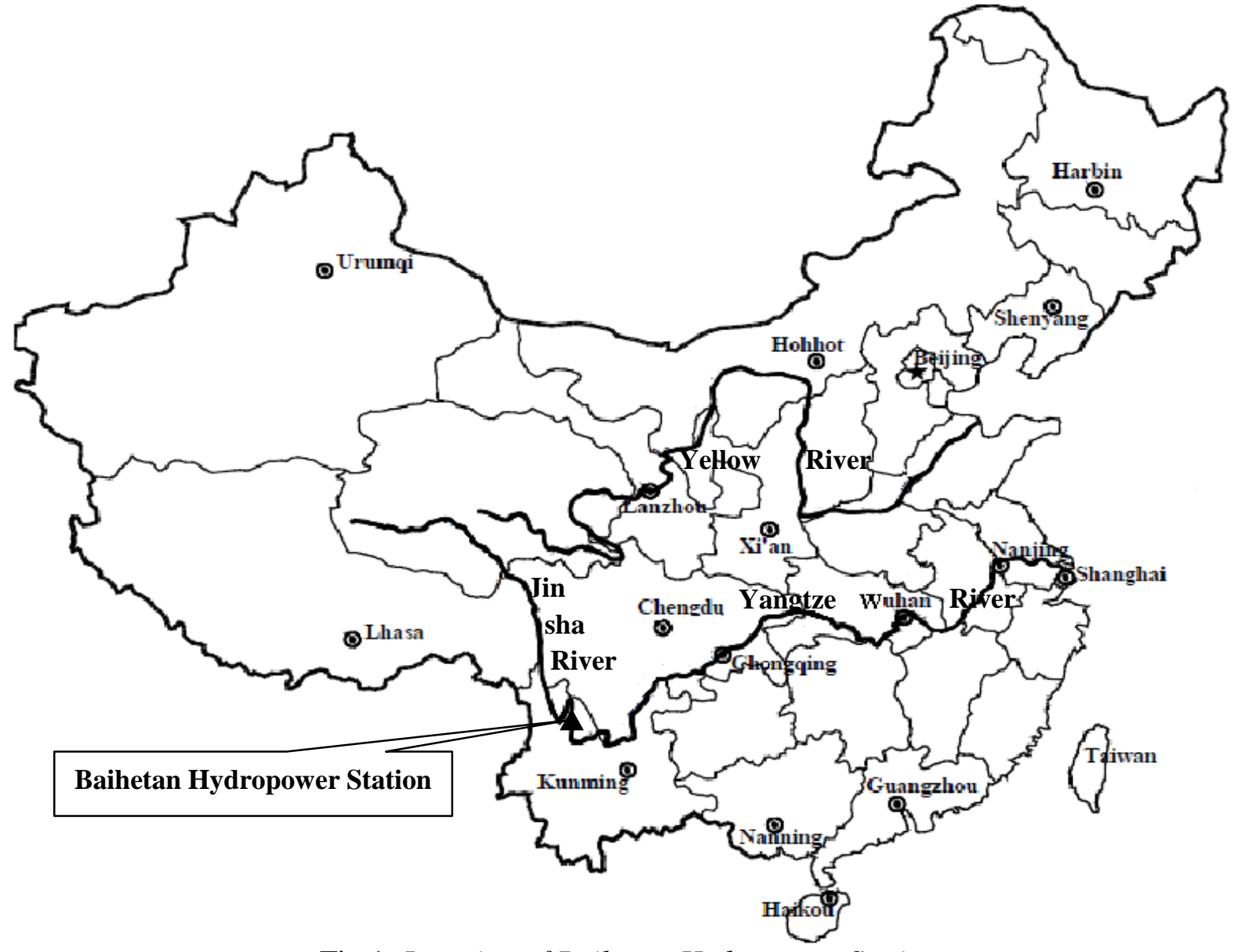

Fig.1. Location of Baihetan Hydropower Station. 


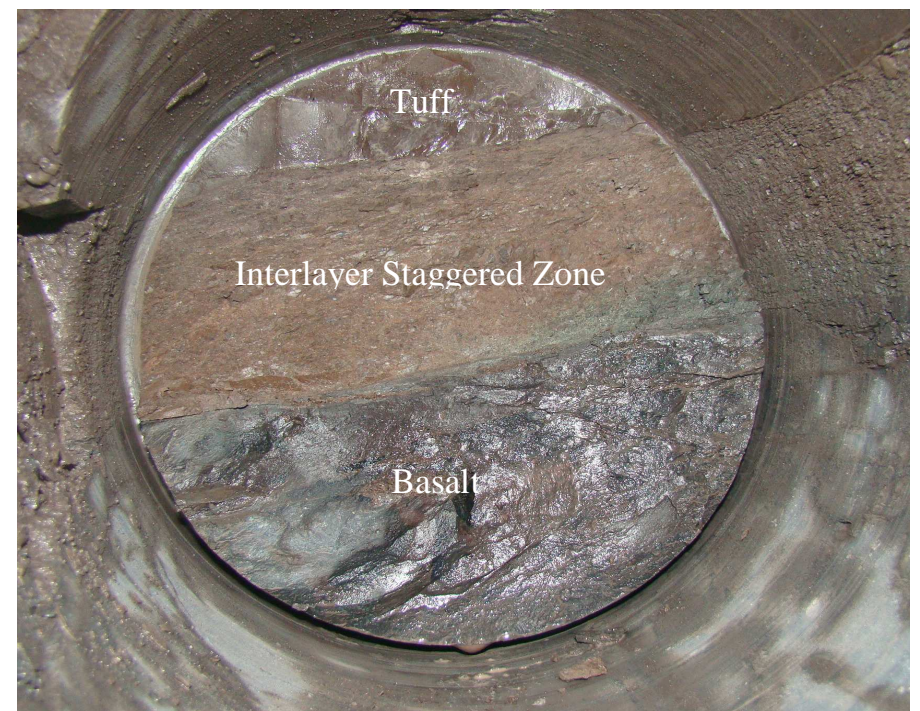

Fig.2. Interlayer staggered zone in testing tunnel No.62. 


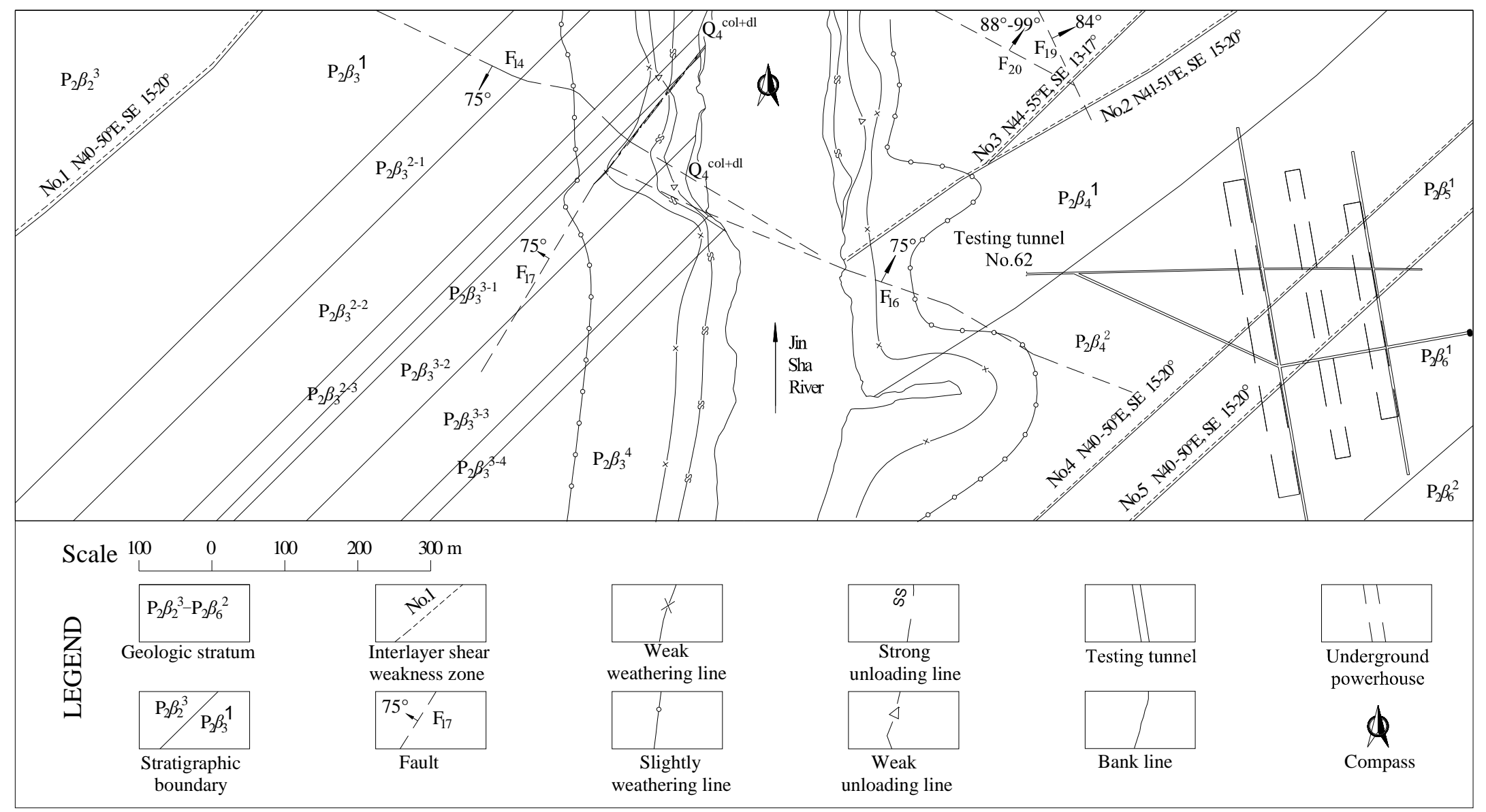

Fig.3. Geological map at an elevation of $624 \mathrm{~m}$ where testing tunnel No.62 is located (1) $\mathrm{P}_{2} \beta_{2}{ }^{3}$ : Aphanitic basalt, amygdaloidal basalt, breccia lava; (2) $\mathrm{P}_{2} \beta_{3}{ }^{1}$ : Aphanitic basalt, breccia lava with oblique basalt and amygdaloidal basalt with oblique basalt; (3) $\mathrm{P}_{2} \beta_{3}{ }^{2-1}$ : Amygdaloidal basalt; (4) $\mathrm{P}_{2} \beta_{3}{ }^{2-2}$ : Columnar jointed basalt; (5) $\mathrm{P}_{2} \beta_{3}{ }^{2-3}$ : Breccia lava; (6) $\mathrm{P}_{2} \beta_{3}{ }^{3}$ : Columnar jointed basalt; (7) $\mathrm{P}_{2} \beta_{3}{ }^{4}$ : Amygdaloidal basalt, aphanitic basalt and breccia lava; (8) $\mathrm{P}_{2} \beta_{3}{ }^{5}$ : Oblique basalt, breccia lava; (9) $\mathrm{P}_{2} \beta_{4}{ }^{1}$ : Columnar jointed basalt, amygdaloidal basalt, breccia lava and microcrystalline basalt; (10) $\mathrm{P}_{2} \beta_{4}{ }^{2}$ : Amygdaloidal basalt, breccia lava; (11) $\mathrm{P}_{2} \beta_{5}{ }^{1}$ : Aphanitic basalt and amygdaloidal basalt; (12) $\mathrm{P}_{2} \beta_{6}{ }^{1}$ : Columnar jointed basalt and breccia lava; (13) $\mathrm{P}_{2} \beta_{6}{ }^{2}$ : Aphanitic basalt and breccia lava; (14) $\mathrm{Q}_{4}{ }^{\text {col+dl }}$ : Quaternary unconsolidated deposits. 


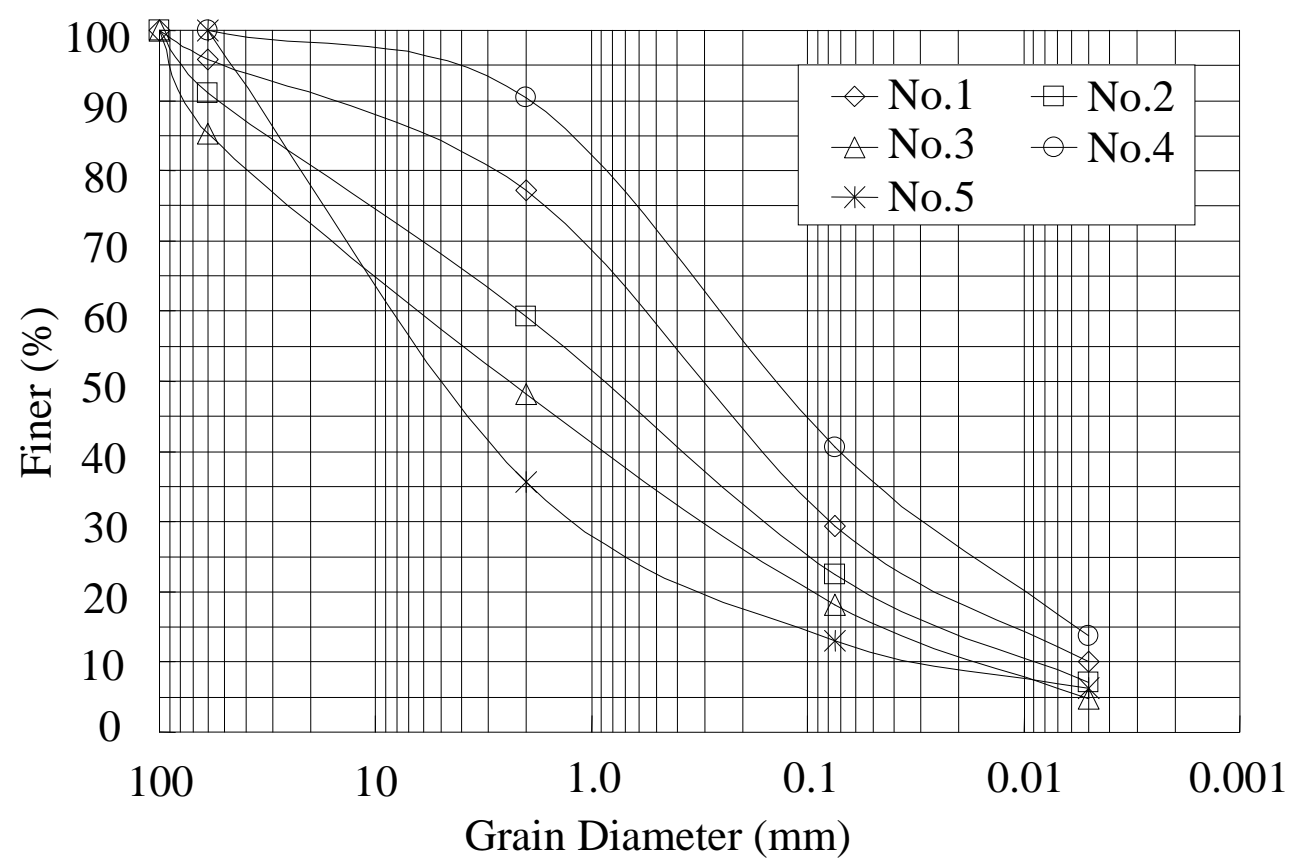

Fig. 4. Grain size distribution of interlayer material.

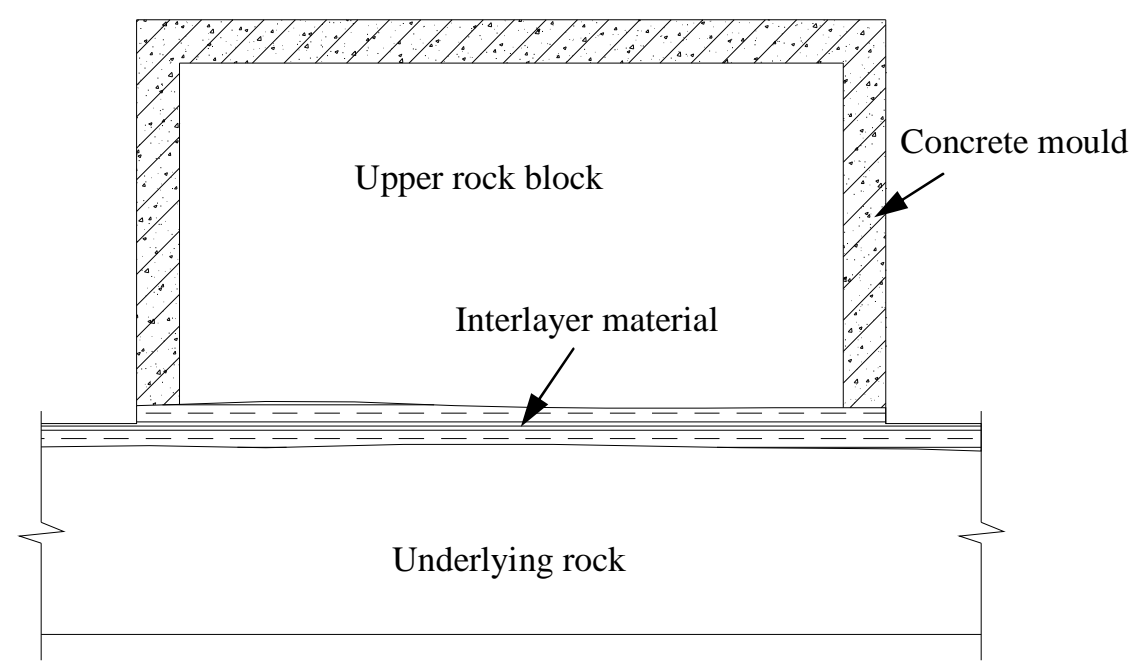

Fig. 5. The sketch of sample for the in-situ direct shear test 


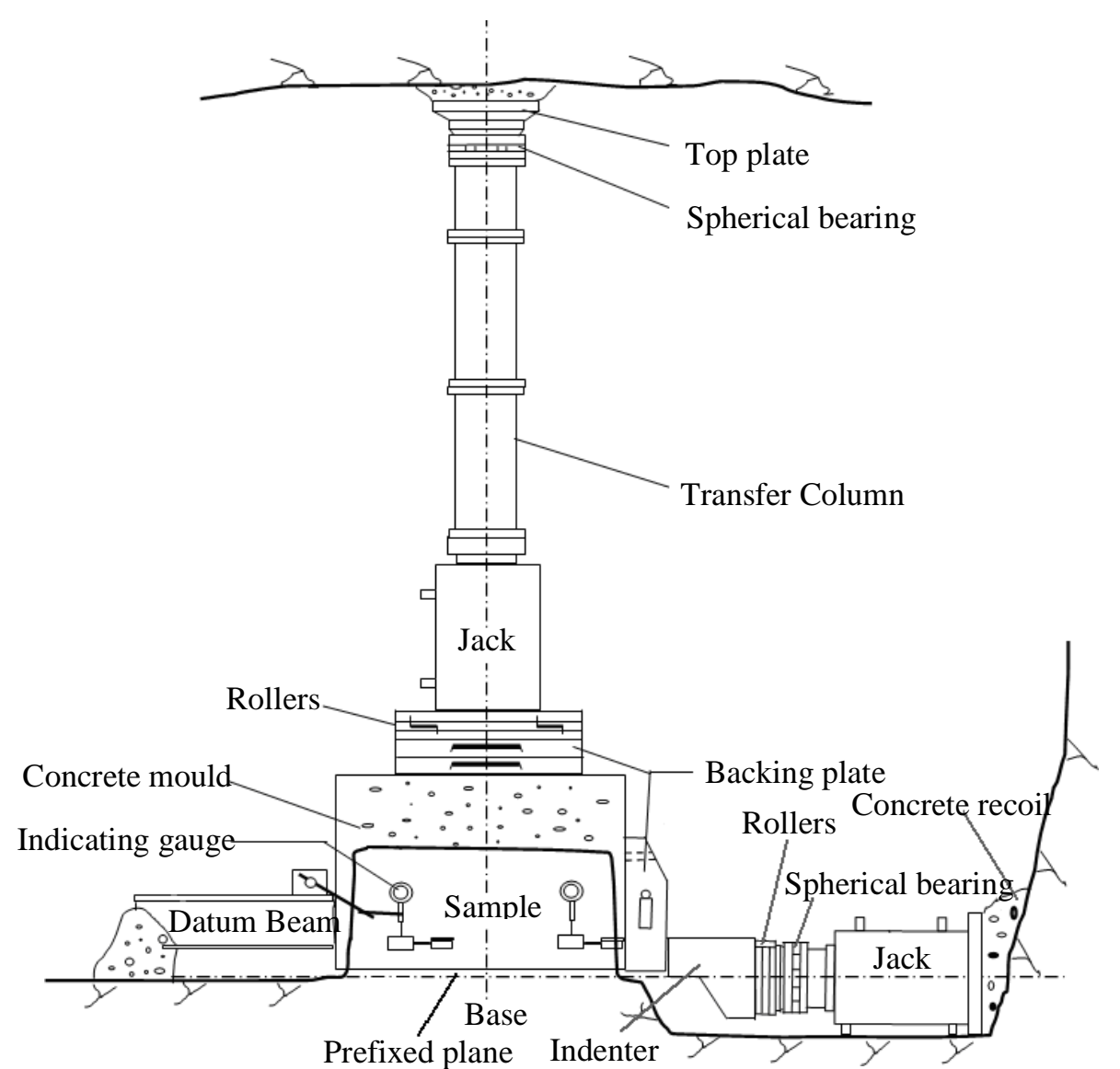

Fig.6. Schematic layout of in-situ direct shear test.

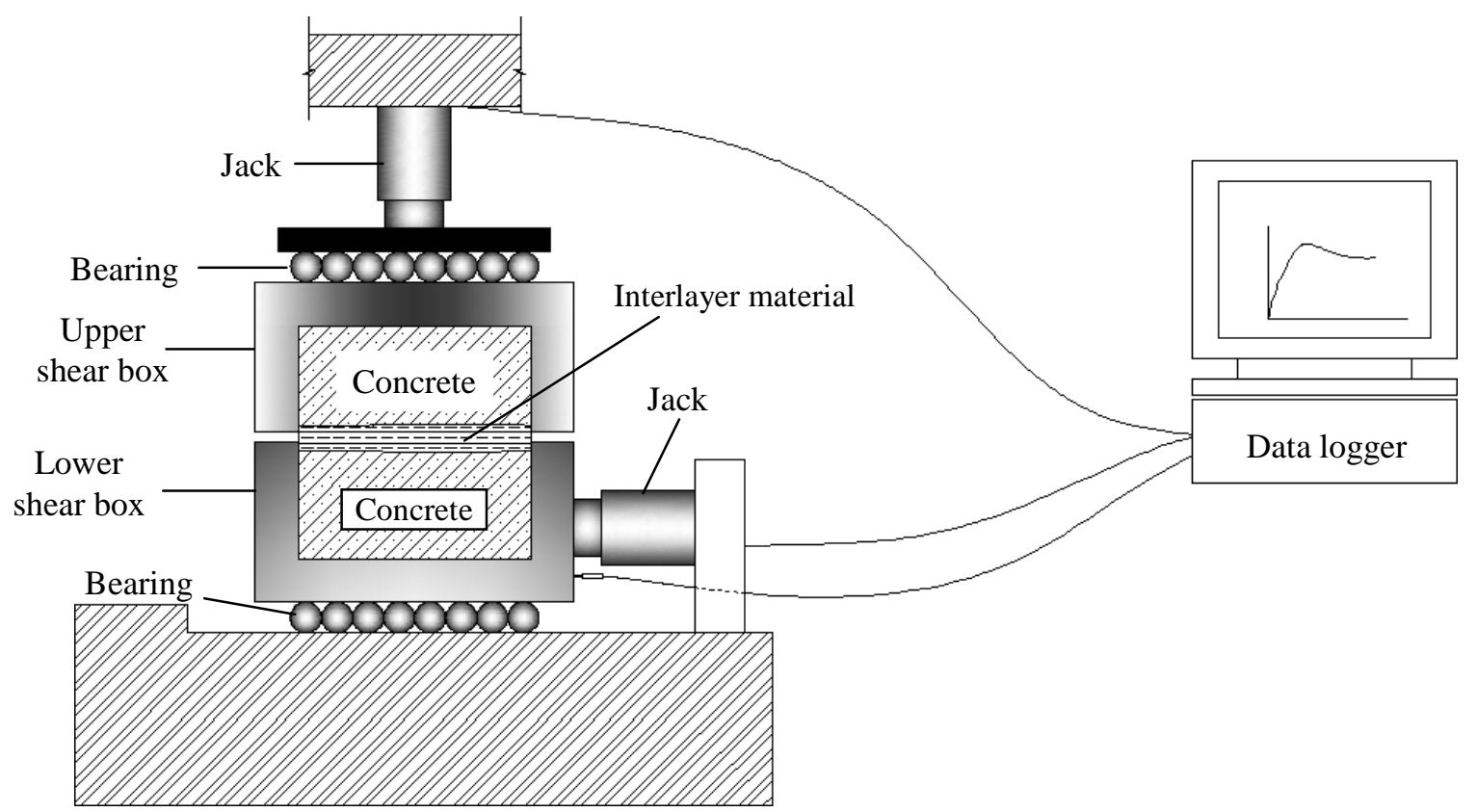

Fig.7. Schematic diagram of RMT150C. 


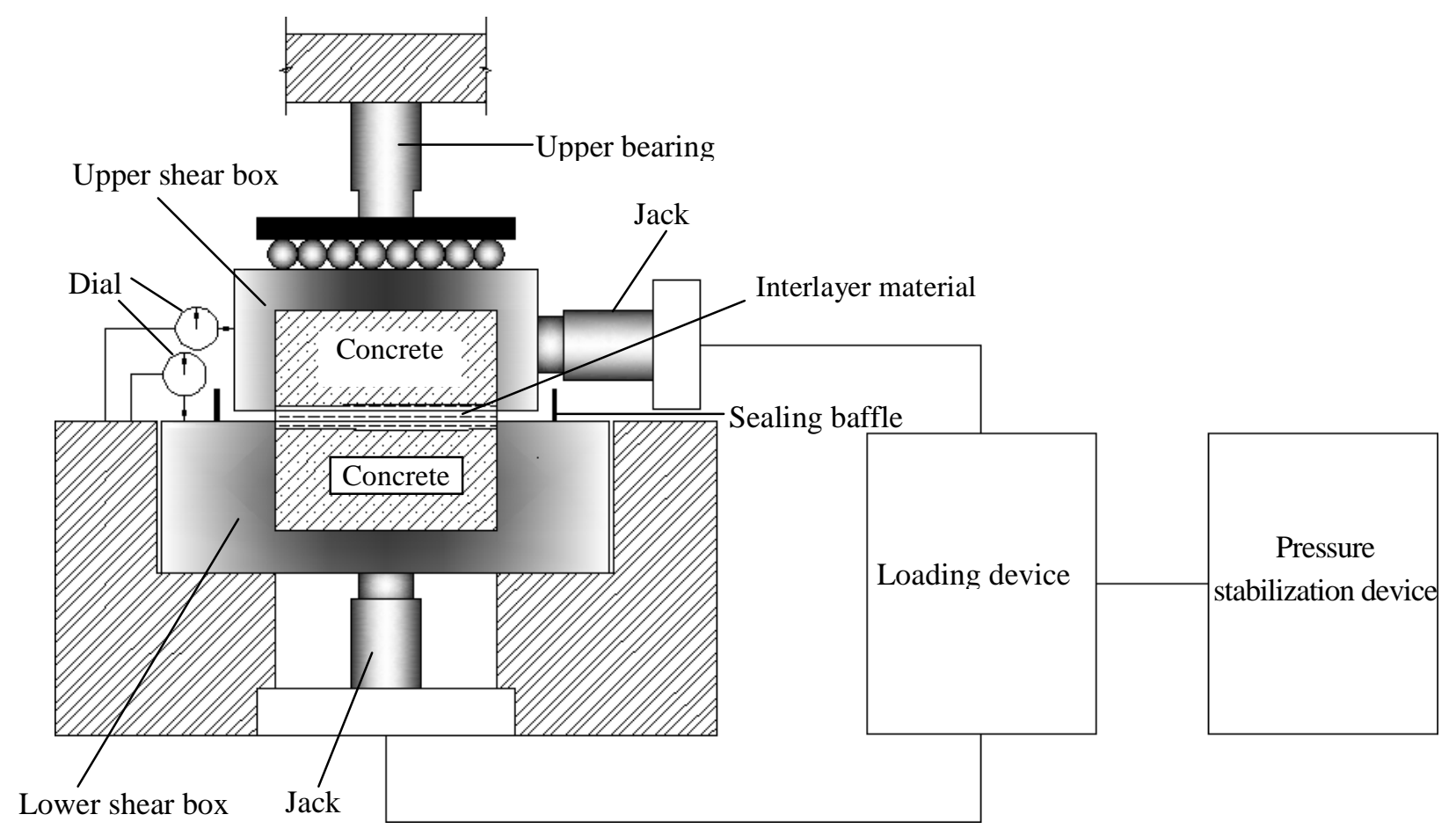

Fig.8. Schematic diagram of JQ-200. 


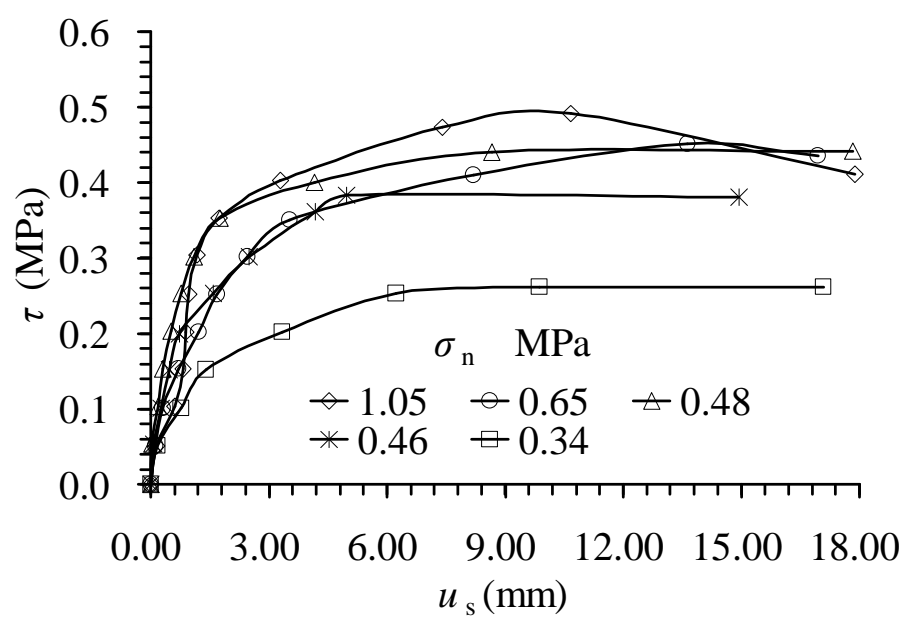

(a)

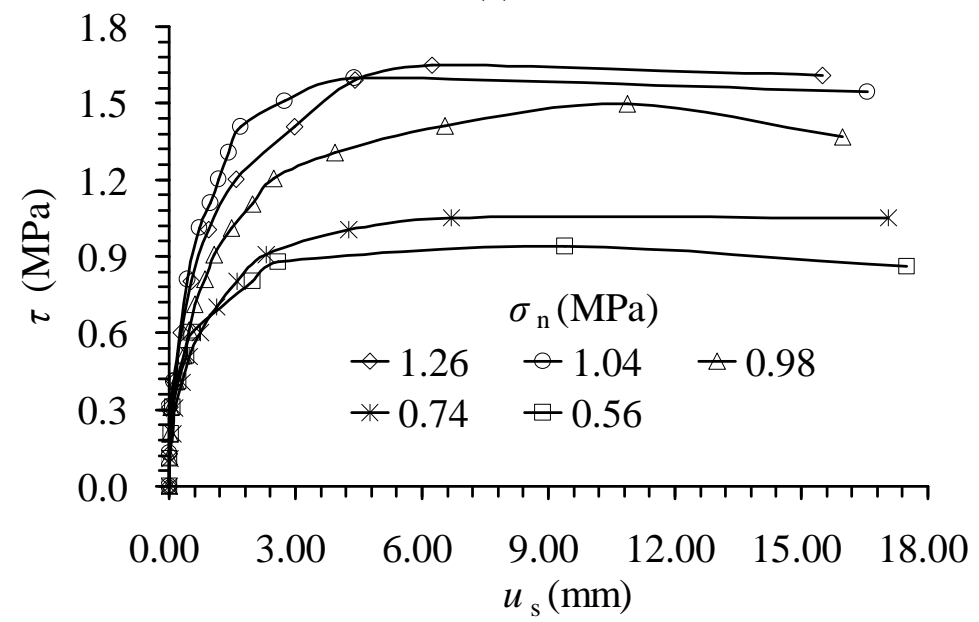

(b)

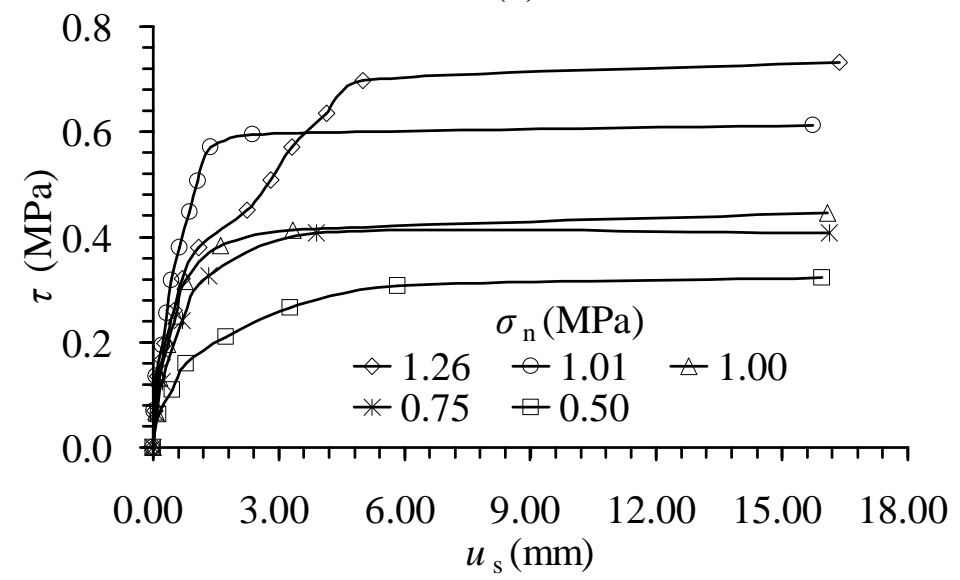




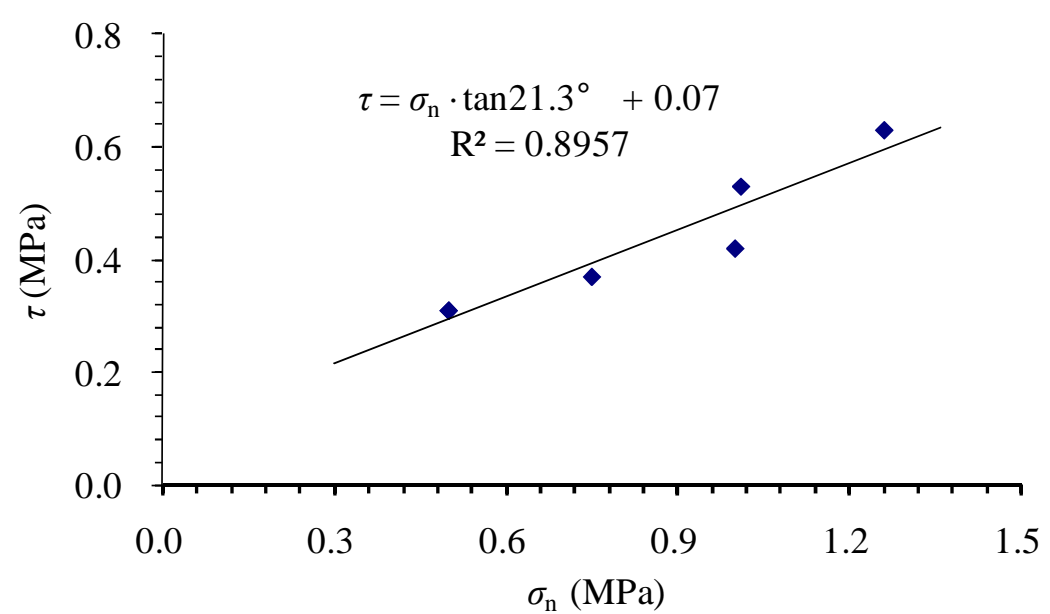

(c)

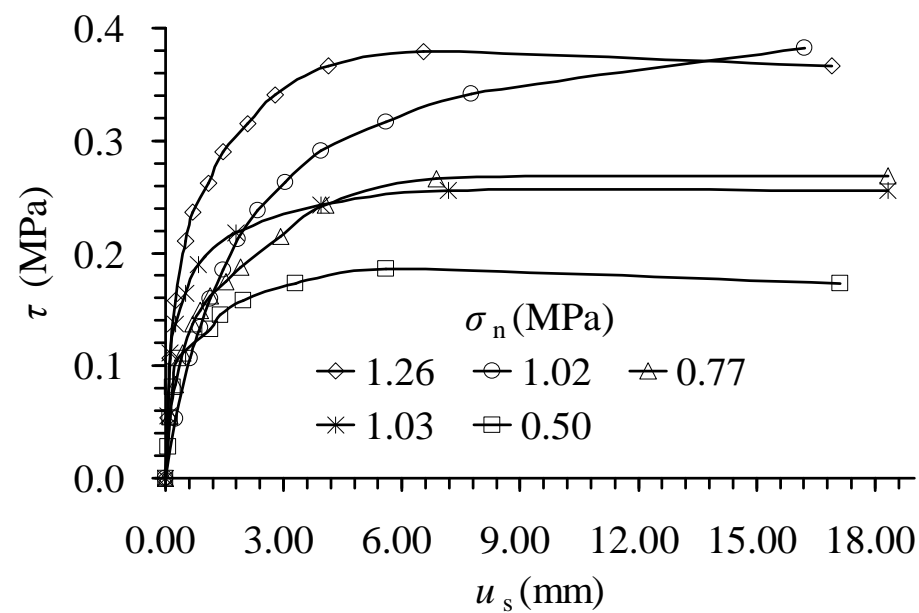

(d)

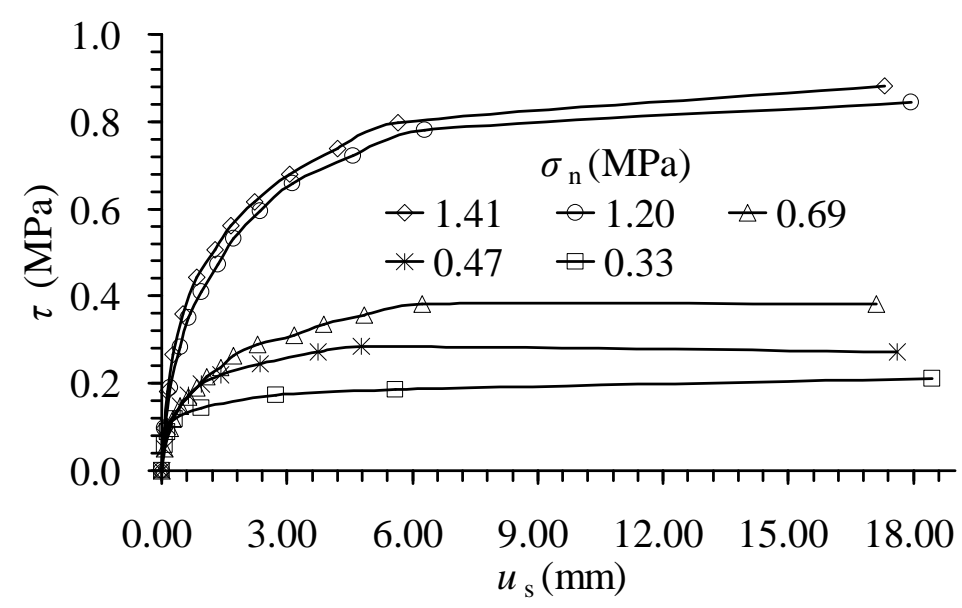

Fig.9. Typical results of interlayer materials of in-situ direct shear tests where the size of sample is $500 \mathrm{~mm} \times 500 \mathrm{~mm} \times 350 \mathrm{~mm}$ : from the interlayer staggered zone No.1 at an initial degree of saturation $S_{r}=76.6 \%$ (a), from the interlayer staggered zone No.2 at an initial $S_{r}=73.0 \%(b)$, from the interlayer staggered zone No.3 at an initial $S_{r}=96.6 \%$ (c), from the interlayer 
staggered zone No.4 at an initial $S_{r}=93.5 \%(d)$, and from the interlayer staggered zone No.5 at an initial $S_{r}=76.6 \%(e)$.

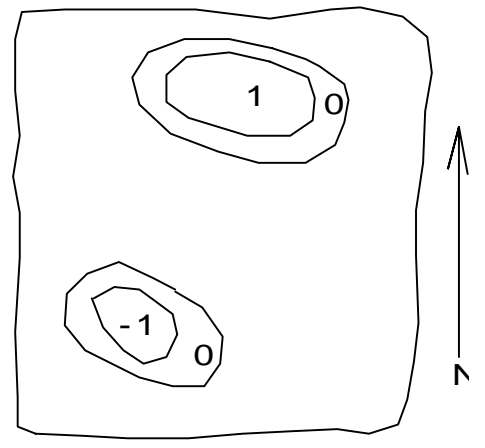

(a)

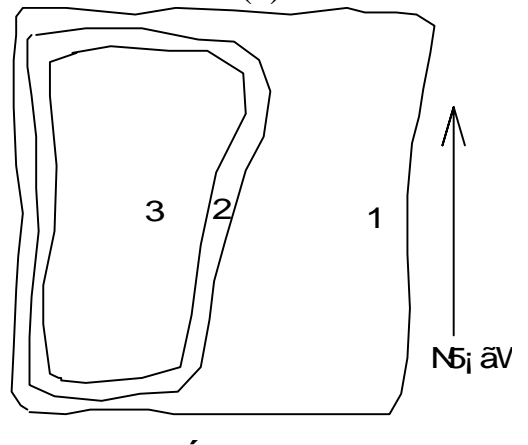

(b)

Fig.10. The shear surfaces of samples for a set of in-situ shear tests in zone 4: (a) normal shear surface, $(b)$ irregular shear surface. The unit of numbers is centimeter, the negative number means the region is below the prefixed shear plane and the arrowhead points at the shear direction.

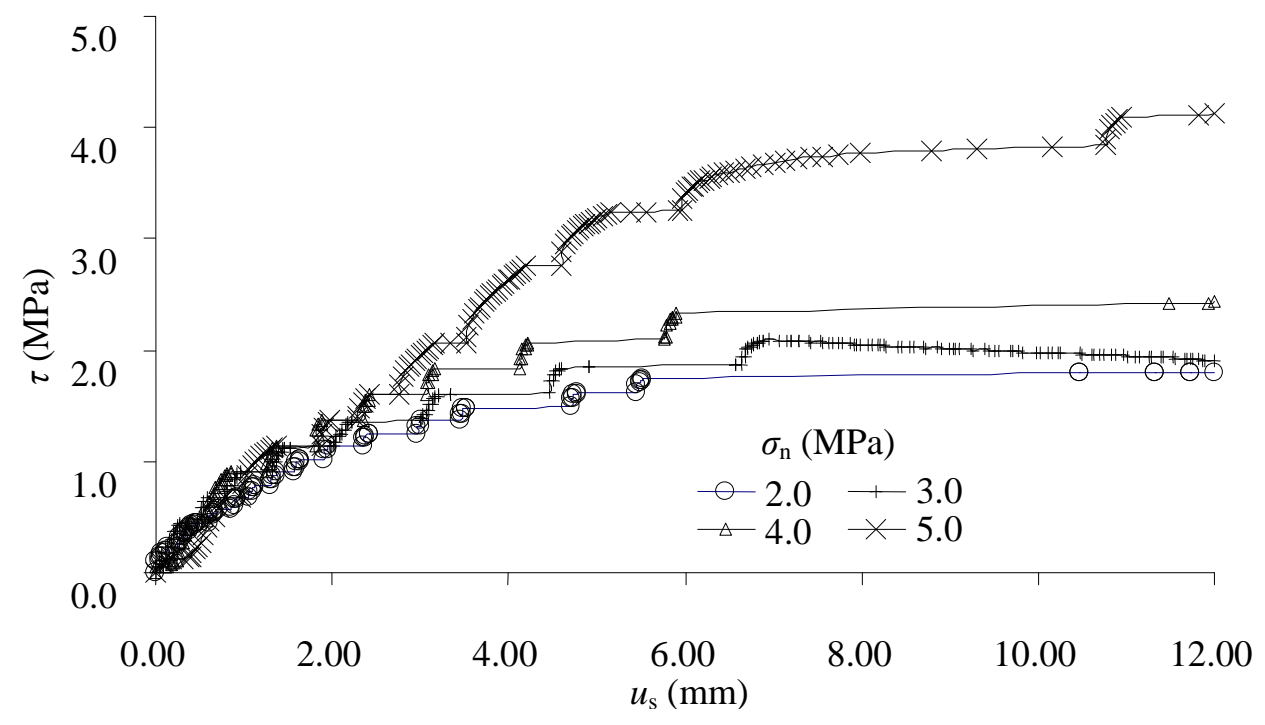




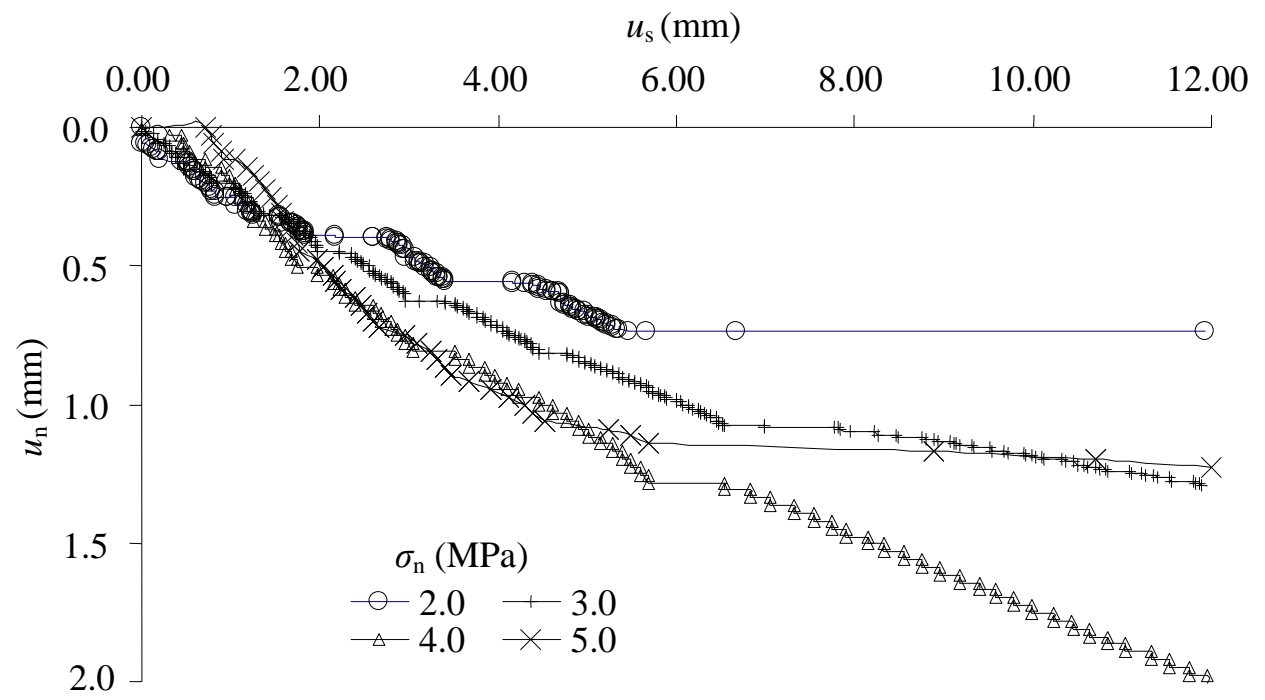

Fig.11. Typical results of interlayer materials from laboratory direct shear test by MSM (the size of sample is $150 \mathrm{~mm} \times 150 \mathrm{~mm} \times 150 \mathrm{~mm}$ ) on the interlayer material from testing tunnel No.62 with the initial degree of saturation between $17.9 \%$ and $48.7 \%$.

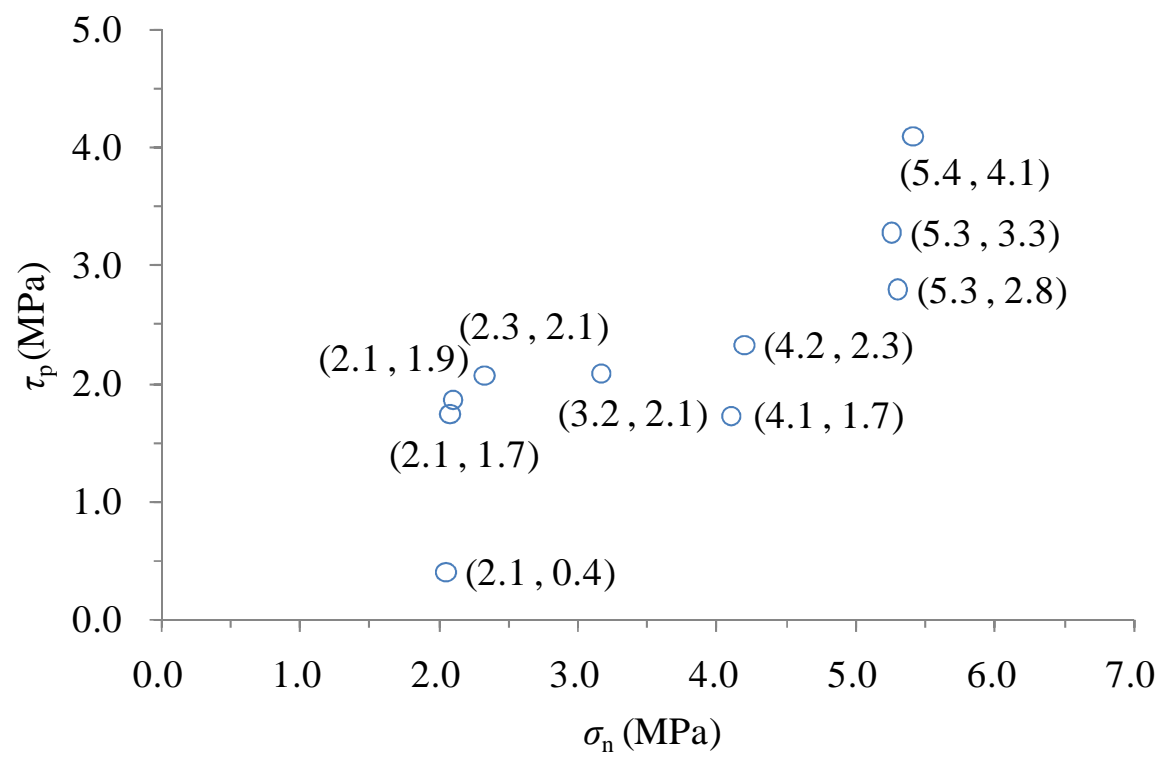

Fig.12. Shear stress versus normal stress of laboratory direct shear test on interlayer material by MSM. 

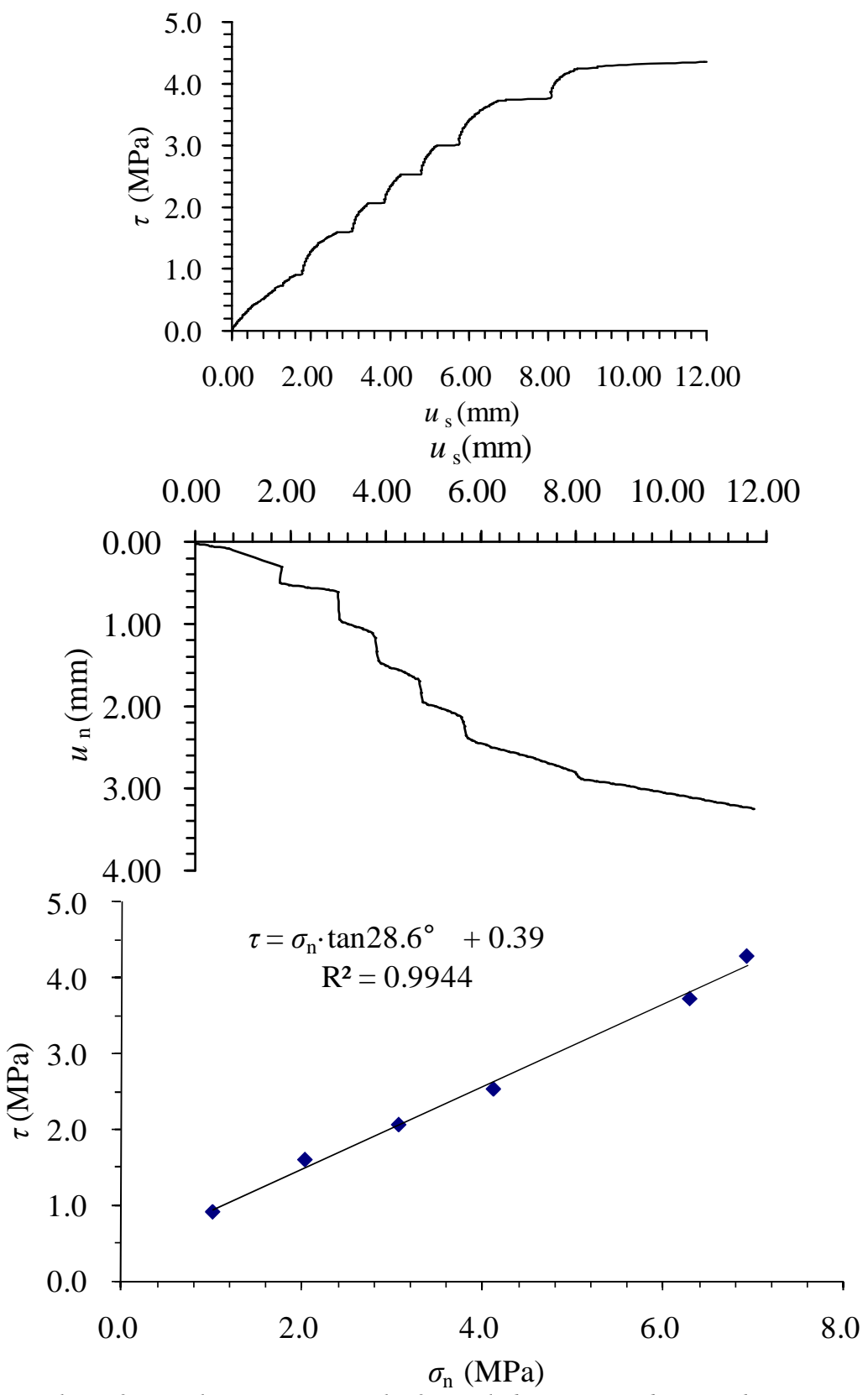

Fig.13. Typical results of interlayer materials from laboratory direct shear test by SSM (the size of sample is $150 \mathrm{~mm} \times 150 \mathrm{~mm} \times 150 \mathrm{~mm}$ ) on the interlayer material from testing tunnel No.62 at an initial degree of saturation $\mathrm{Sr}=33.1 \%$. 


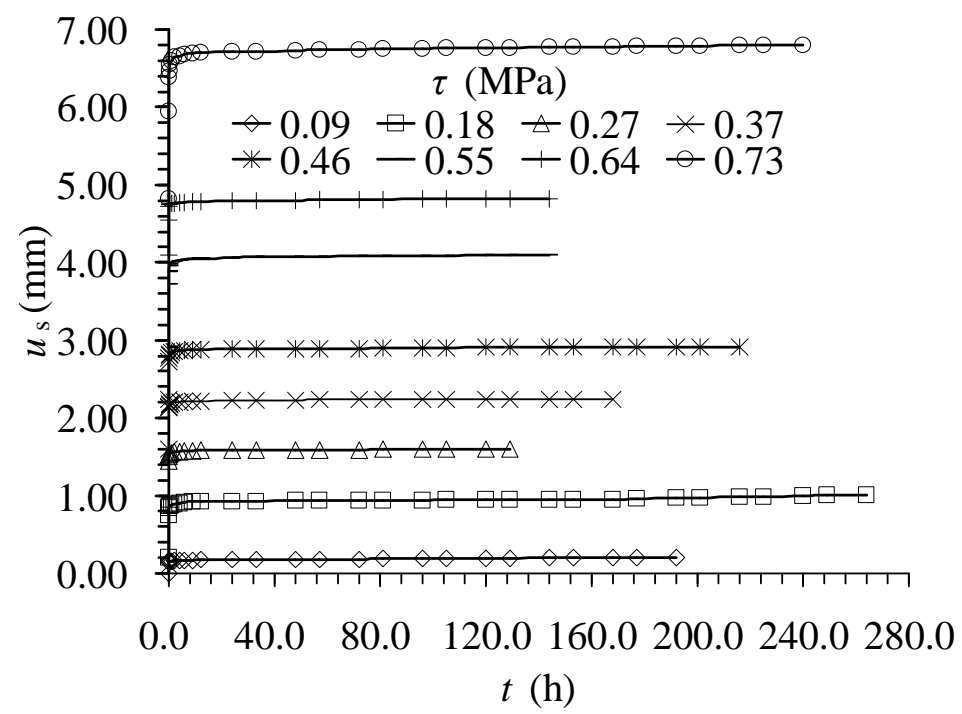

Fig.14. Typical results of shear creep test on interlayer material from testing tunnel No.4lat an initial degree of saturation $S_{\mathrm{r}}=24.2 \%$ under an initial normal stress $\sigma_{\mathrm{n}}=0.49 \mathrm{MPa}$.

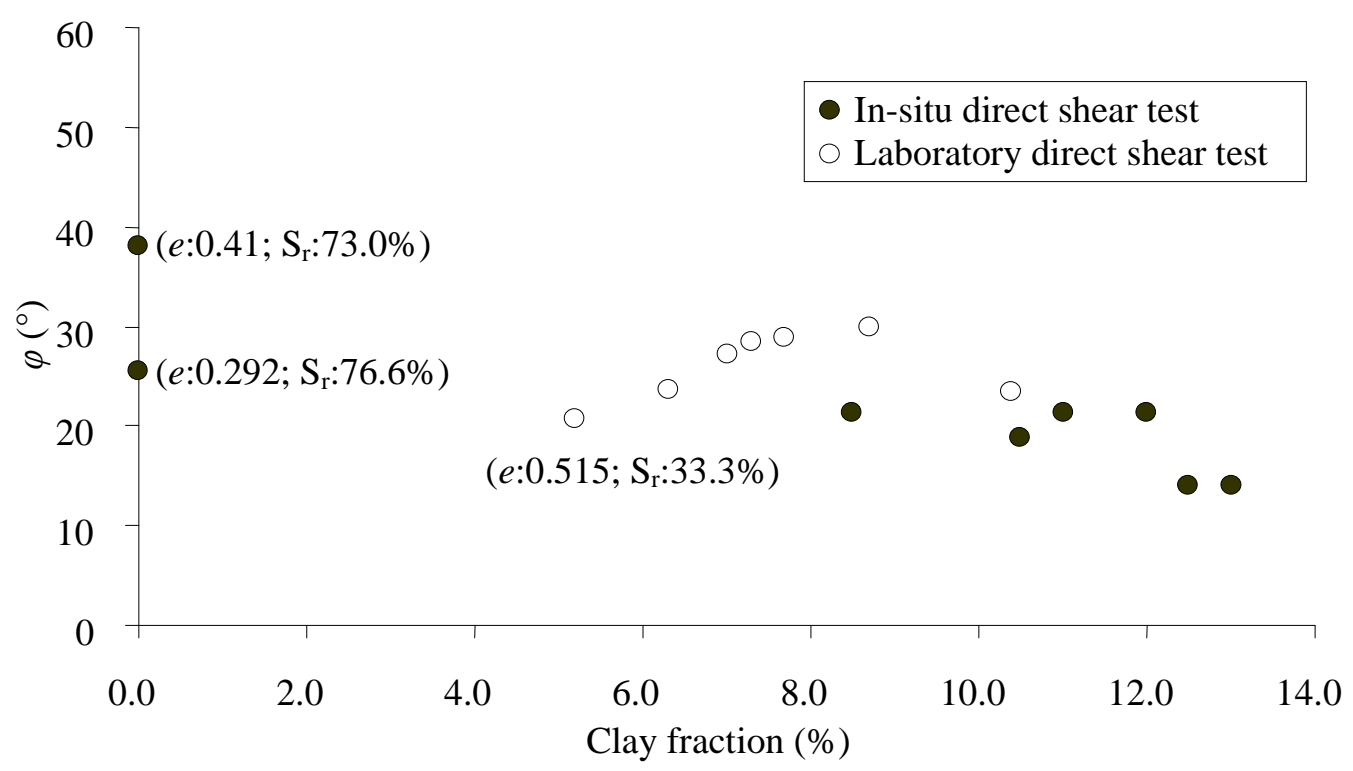

a 


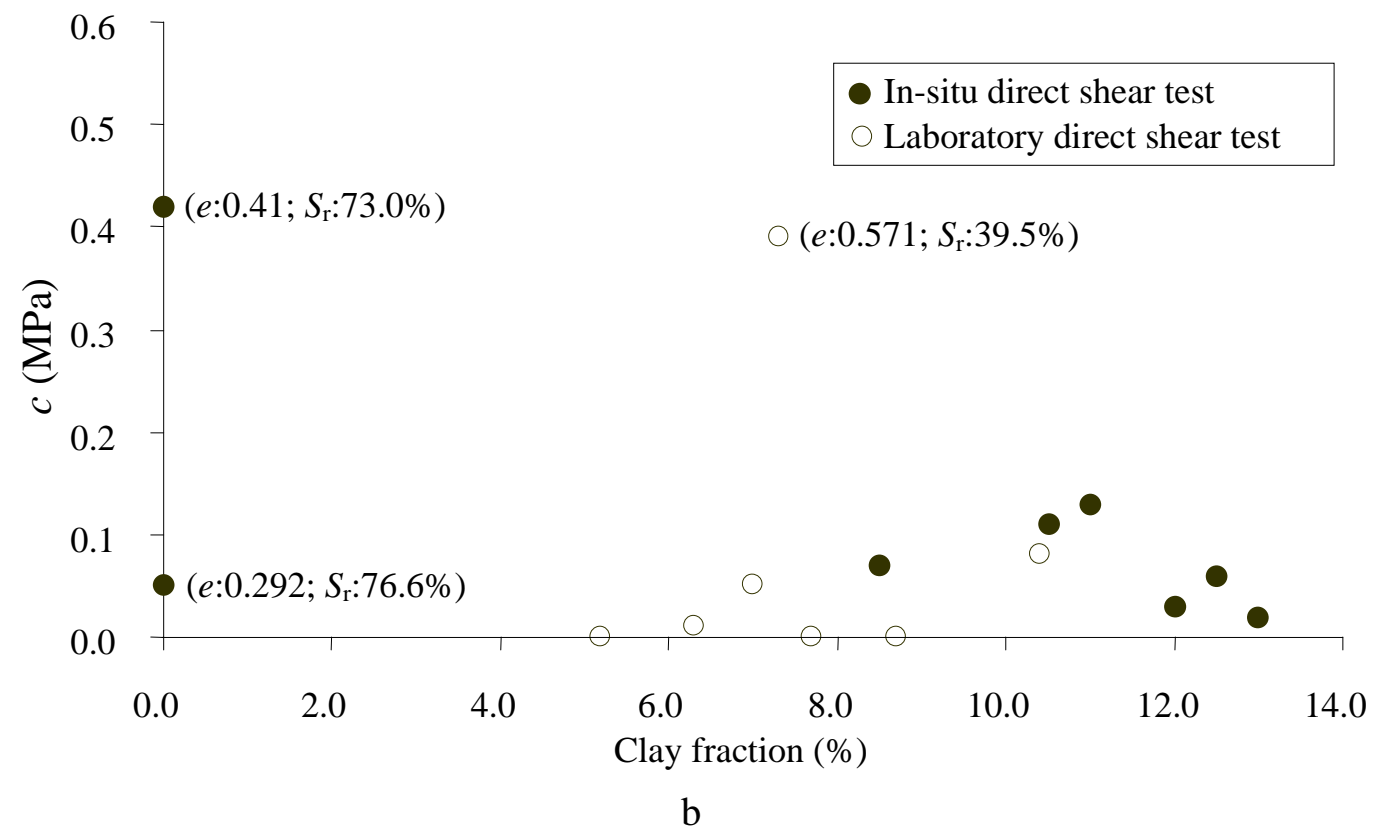

Fig.15. Strength parameters versus clay fraction; (a) friction angle, (b) cohesion. 


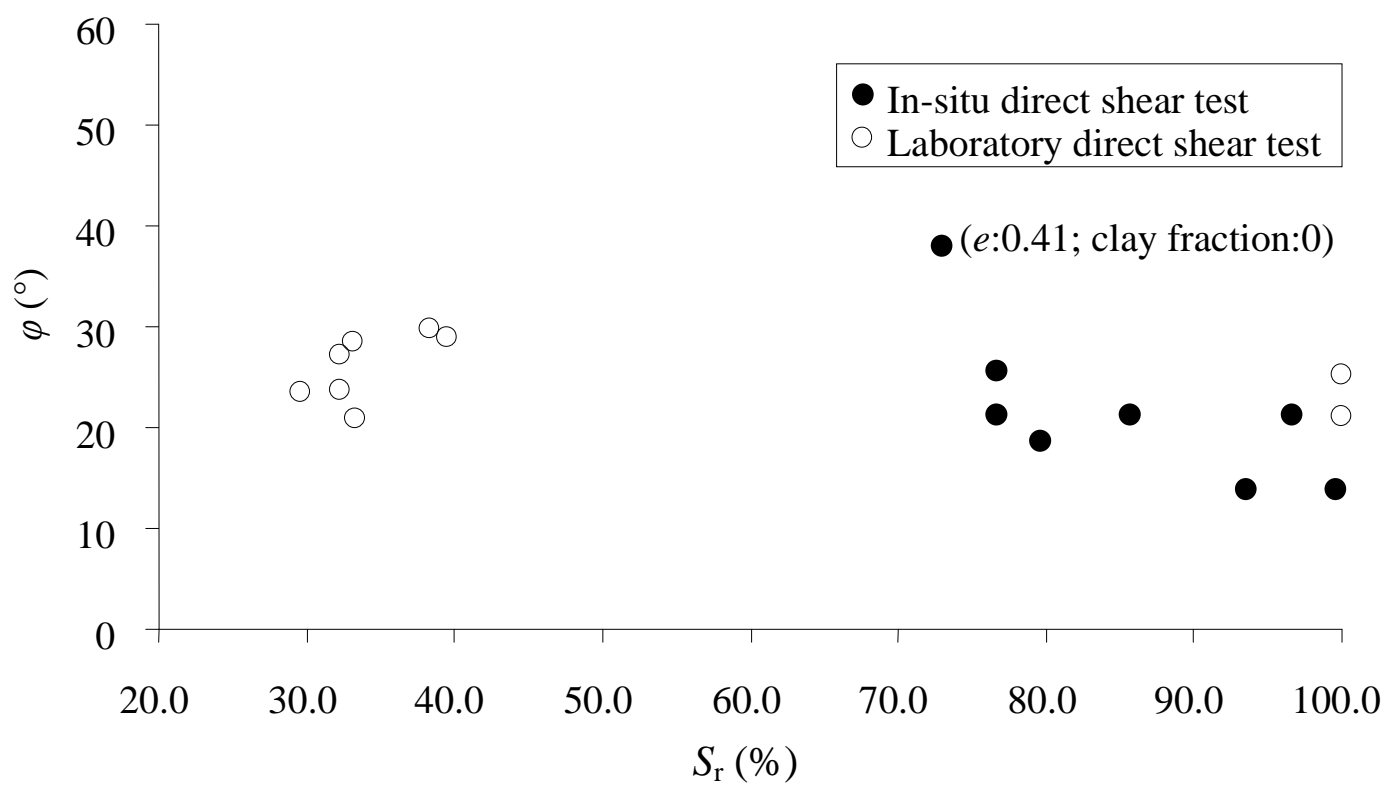

a

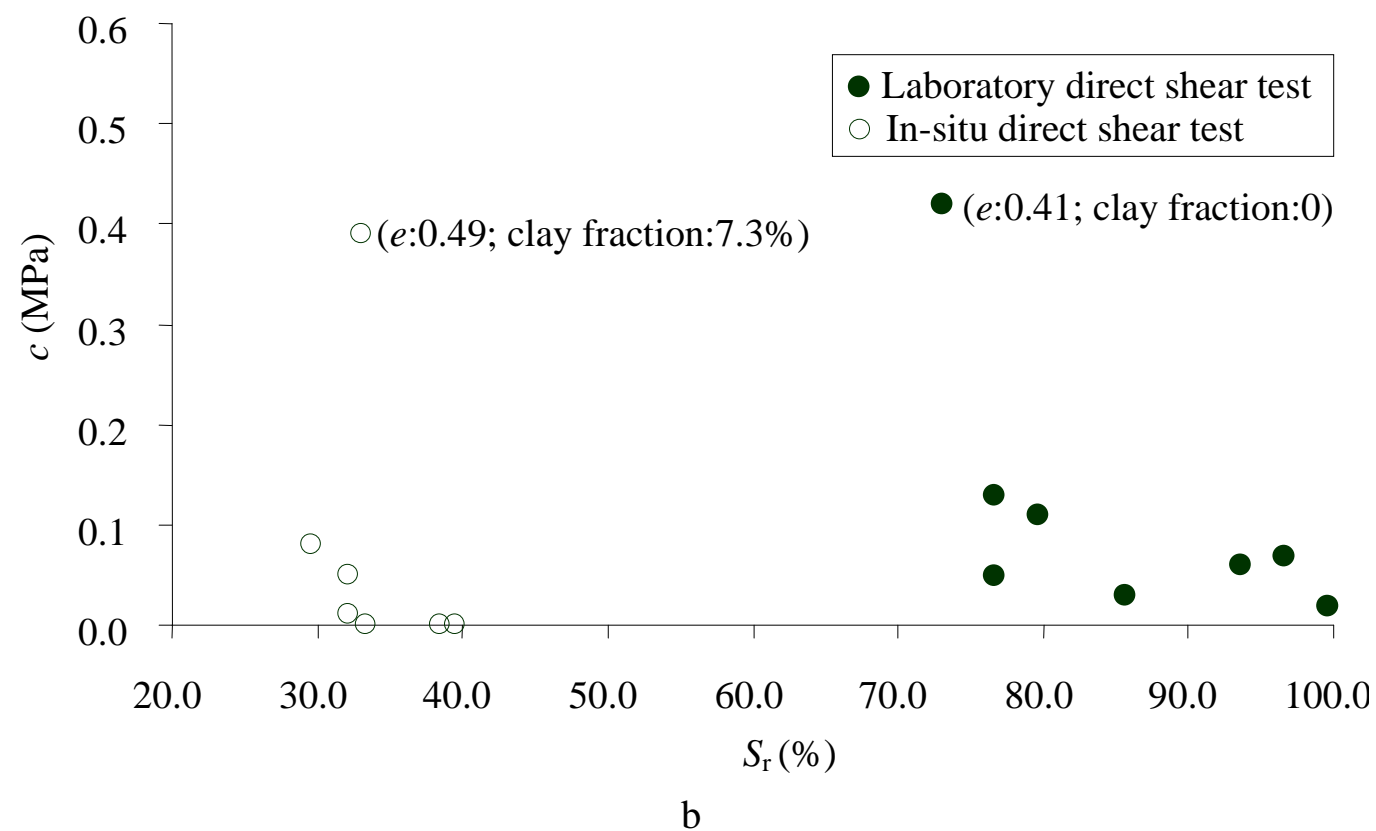

Fig.16. Strength parameters versus initial degree of saturation; (a) friction angle, (b) cohesion. 